Article available at nttp://WwW.parasite-journal.org or nttp://dx.dol.org/10.1051/parasite/1997042107

\title{
Eighty-year research of Phlebotomine sandflies (Diptera: PSYChOdidae) In China (1915-1995). I. TAXONOMY AND ZOOgEographical Distribution
}

\author{
LENG Y.J.*
}

\section{Summary :}

County-wide surveys for phlebotomine sandflies were made during the past 80 years in China and a total of 43 confirmed species were identified including one most primitive living fossil genus Chinius - and 5 incriminated vectors of leishmaniasis. These works were mainly carried out by the author and his colleagues. In the first part of this paper the taxonomy and zoogeographical distribution of Chinese species are given.

KEY WORDS : Phlebotomine sandfly, taxonomy, distribution, China, leishmaniasis.

The Chinese phlebotomine sandflies (PS) have been studied since the early part of this century. A physician of Tsinghua College, R.A. Bolt (1915), reported this tiny insect from his campus in the vicinity of Beijing and a survey made by him based upon the materials from Christian Missionary Hospitals over China and Korea. His specimens collected from Wofesi (Lying Buddha Temple) in west suburb, Beijing was named Phlebotomus major chinensis by Newstead (1916) and adapted to P. chinensis by Sinton (1928) which was later proved to be a vector of visceral leishmaniasis (VL) in China. Apart from some local endemic area scattered in the northwestern Sichuan and northern Hubei, VL had been known to occur in epidemic form in North, Northeast, East and Northwest China mainly along the Huanghe (Yellow) River, the birth place of China's ancient culture and the north of Changjiang (Yangtze) River. It covered an area about 1,200,000 square $\mathrm{km}$ and epidemicity was about $1-5$ per thousand and 530,000 cases were estimated to occur. Therefore VL had been one of the main parasitic diseases both in China and the world.

Much has been changed after these eighty years. An active study and control of Chinese VL and its vector

\footnotetext{
* Department of Medical Parasitology, Jinan Faculty of Medicine, University, Guangzhou, 510632 China PR.

Tel. 86-20-8551-6511 ext. 4653/4629

e-mail: oyxy@maina.jnu.edu.cn
}

Résumé : 80 ANS DE RECHERCHE SUR LES PhLÉBOTOMES (DipteRA Psychodidae) EN CHINE (1915-1995). I - TAXONOMIE ET RÉPARTITION GÉOGRAPHIQUE

Les études régionales effectuées en Chine au cours des 80 dernières années ont permis d'identifier 43 espèces confirmées, dont un genre considéré comme fossile - Chinius - et 5 vecteurs incriminés dans la leishmaniose. La plupart de ces travaux ont été menés par l'auteur et son équipe. Dans la première partie de cet article sont décrites la taxonomie et la distribution géographique des espèces chinoises.

MOTS CLÉS : Phlébotomes, taxonomie, distribution, Chine, leishmaniose.

PS were carried out from 50's to 60's through thousands of scientists, doctors and paramedicals under the organization of People's Government; and it seems to be a real prospect of eradicating VL from large areas of China (Wang \& Wu 1956; Wang et al., 1983). But during and after the political catastrophe occurred from 60's to 70's, the system of control and prevention suffered a severe setback. This disease and the vector seem to reappear in the area where VL had been considered to be eradicated (Cross et al., 1985; Yan, 1988; Yan et al., 1989a, 1993; Yu et al., 1992). Nevertheless, Chinese VL still exists along the Old Silk Road from Xinjiang eastwards via Gansu, Shaanxi to eastern Inner Mongolia in a sporadic form and some local foci are found in northwestern Sichuan and northern Hubei; but as a fact the risk of recurrence exists, and new type of lymph gland leishmaniasis in Gansu (Zhong et al., 1982) and cutaneous leishmaniasis (CL) in Xinjiang (Xu et al., 1989) and native case of CL in Taiwan (Cross et al., 1985a) have been divided into two species, Le. donovani s.l. and Le. infantum (Xu et al., 1984; New \& Leng, 1985). It is considered that VL was widely epidemic in the old VL area being caused by Le. donovani s.l. and VL still exists along the Old Silk Road being caused by Le. infantum. Four more PS other than $P$. chinensis are incriminated as the vectors of $\mathrm{VL}, P$. alexandri, $P$. longiductus, $P$. sichuanensis and $P$. smirnovi (syn. P. wui). The author reviewed Chinese VL 1949-1959 (Leng, 1982) and 1960-1986 
(Leng, 1988) and PS research in China 1915-1987 (Leng, 1988). An all round survey of PS over China including three metropolises, 27 provinces and autonomous regions and Hong-Kong, Macau has been carried out and about 44 species have been confirmed, including a living fossil primitive fly genus Chinius Leng, 1987. Many works on ecology, taxonomy, evolution, relation to disease transmission and control have been carried out during these eighty years.

\begin{tabular}{|c|c|}
\hline & SOME ABBREVIATIONS IN TEXT \\
\hline CL & $=$ Cutaneous Leishmaniasis \\
\hline Eng. abstr. & $=$ English abstract \\
\hline FMJNU & $\begin{aligned}= & \text { Department of Medical Parasitology, } \\
& \text { Faculty of Medicine, Jinan University, } \\
& \text { Guangzhou, } 510632 \text { China PR }\end{aligned}$ \\
\hline GYMC & $\begin{aligned}= & \text { Department of Parasitology, Guiyang } \\
& \text { Medical College, } 4 \text { Beijing Road, Guiyang, } \\
& \text { Guizhou Province, } 550004 \text { China, PR }\end{aligned}$ \\
\hline LSTM & $\begin{aligned}= & \text { Liverpool School of Tropical Medicine, } \\
& \text { Pembroke Place, Liverpool, L3 5QA United } \\
& \text { Kingdom }\end{aligned}$ \\
\hline NHML & $\begin{aligned}= & \text { Department of Entomology, Natural History } \\
& \text { Museum, Cromwell Road, London SW7 } \\
& \text { 5BD United Kingdom }\end{aligned}$ \\
\hline PS & $=$ Phlebotomine Sandfly \\
\hline SDIPD & $\begin{aligned}= & \text { Shandong Institute of Parasitic diseases, } 13 \\
& \text { Middle Taibai Road, Jining, Shandong Pro- } \\
& \text { vince, } 272133 \text { China, PR }\end{aligned}$ \\
\hline SIPD & $\begin{aligned} &= \text { Shanghai Institute of Parasitic Diseases, Chi- } \\
& \text { nese Academy of Medical Sciences, } 207 \\
& \text { Ruijin 2nd Road, Shanghai, } 200025 \text { China, PR }\end{aligned}$ \\
\hline VL & $=$ Visceral Leishmaniasis \\
\hline ZUMS & $\begin{aligned}= & \text { Department of Parasitology, Zhongshan } \\
& \text { University of Medical Sciences, Zhongshan } \\
& \text { 2nd Road, Guangzhou, } 510089 \text { China, PR }\end{aligned}$ \\
\hline
\end{tabular}

Part I is written mainly from the papers of Leng \& Zhang (1991, 1993). To complete the features for the taxonomy of Chinese PS, their corresponding references are given and the following published and communication materials are included: 1. Regular periodicals and books in later years; 2 . Unpublished PS survey made by Anti-epidemic Stations in different level; 3. PS survey published in University Bulletin for postgraduates; 4. Annual reports from Institutes; 5. (Epidemiology and Medical Animals of China) edited by the Department of Military Health, published by General Logistics Department, PLA, Beijing in 1979. For correctness, the name of places is revised with geographical dictionaries edited by the Bureau of National Territory.

(..) : Number of towns, counties and cities where the species is distributed in one province, metropolis, autonomous region or special area.

[..] : Number of towns, counties and cities where the species is distributed in China.

\{..\} : Number of provinces, metropolises, autonomous regions and/or special area where one species is distributed.

\section{A. Genus Chinius Leng, 1987 \\ [Leng, YJ: Ann. Trop. Med. Parasitol., 1987a, 81(3):331-337]}

Only one cave dwelling species known: Chinius junlianensis.

Holotype \& Paratypes: FMJNU \& NHML

Taxonomy: Chinius has a broad rounded wing and its shape and venation show a close similarity to the fossil fly Phlebotomites brevifilis Hennig, 1972 from Lebanese amber 120 million years old, and somewhat resembles another fossil fly Phlebotomus tipuliformis Meunier, 1905 from Baltic amber of 30 million years old. After the comparison with American phlebotomine Genus Warileya, Leng (1988a) suggested that the Old World and New World phlebotomus were evolved from a same origin Phlebotomites, Chinius morphologically appears to be the most primitive sandfly described, which probably has the shortest labrum among PS, and it is suggested that it may attack amphibians and/or reptiles (Leng, 1987a).

\section{C. junlianensis Leng, 1987 [5] \{4\}}

Holotype \& Paratypes: FMJNU \& NHML

Distribution: Northwest at Junlian $\left(28.1^{\circ} \mathrm{N}, 104.5^{\circ} \mathrm{E}\right)$, Sichuan; Southeastern at Yangshan $\left(24.4^{\circ} \mathrm{N}, 112.6^{\circ} \mathrm{E}\right)$, Guangdong; it covers 5 counties of one autonomous region and three provinces in South and Southwest China limestone mountains. Guangdong: Yangshan; Guangxi: Debao, Lingyun; Guizhou; Qinglong; Sichuan: Junlian.

\section{B. Genus Grassomyia Theodor, 1958}

[Theodor, O: Die Fliegen der Palaearktischen Region, 9c Psychodidae-Phlebotominae, Stuttgart, 1958, p. 47; Abonnenc \& Leger: Cah. ORSTOM, 1976, 14:69-78; Artemiev, MM \& Neronov, VM:

Inst. evol. Morph. anim. Ecol., 1984, pp. 28-31; Leng, YJ: J. Sci. Med. Jinan Univ., 1987, 2:25-29; Lewis, DJ: Syst. Zool., 1987, 12:165-166]

2. G. indica Theodor, 1931 [12] \{6\}

Chinese Specimen: FMJNU

Distribution: North, Kaifeng $\left(34.7^{\circ} \mathrm{N}\right)$, Henan; East Taidong $\left(121.1^{\circ} \mathrm{E}\right)$, Taiwan; Southwest, Yaxian $\left(18.2^{\circ} \mathrm{N}, 109.5^{\circ} \mathrm{E}\right)$, Hainan, which covers 12 counties and cities of one special zone and 5 provinces. G. indica is also found in India, Indonesia, Cambodia, Laos, Malaysia, Nepal, Pakistan and Thailand.

Anhui: Linquan, Taihe; Guangdong: Guangzhou, Zhanjiang; Hainan: Baoting, Lingshui, Yaxian; Henan: Kaifeng: Hong Kong; Taiwan: Gaoxiong, Pingdong, Taidong.

\section{GeNUS IDIOPHLEBOTOMUS QUATE \& FaIRChILD, 1961}

[Quate, LW \& Fairchild, GB: Pacific Insects, 1961, 3(2):208]

3. I. longiforceps Wang, Ku \& Yuan, 1974 [8] \{4\} [Wang, CS, KU, YM \& Yuan, ZC: Acta Entomol. Sin., 1974, 17(3):334-338]

Holotype \& Paratypes: GYMC 
Distribution: Northeast, Jishou $\left(28.3^{\circ} \mathrm{N}, 109.7^{\circ} \mathrm{E}\right)$, Hunan; West, Lùxi $\left(98.5^{\circ} \mathrm{E}\right)$, Yunnan; South, Mengla $\left(21.4^{\circ} \mathrm{N}\right)$, Yunnan of the Southwest Mountainous Area covering 8 counties in one autonomous region and 3 provinces.

Guangxi: Lingyun; Guizhou:Congjiang; Hunan: Jishou; Yunnan: Lùxi, Mengla, Menglian, Simao, Yingjiang.

Southwest Mountainous Region, China seems a place which preserves some primitive PS in the world

\section{Genus Phlebotomus Rondani \& Berte, 1840}

[Rondani, C: Ann. Soc. ent. Fr. 1843, 2(1):263; Theodor, O: Bull. Ent. Res., 1948, 39(1):96]

\section{a. Subgenus Adlerius Nitzulescu, 1931}

[Nitzulescu, V: Ann. Parasit. bum. comp., 1931 a, 9(3):271-275; Theodor, O: 1948:98; 1958:27; Artemiev, MM \& Neronov, VM: Genus Phlebotomus, Moscow, 1984: 107$108]$

Four species of Adlerius have been found in China among which three $-P$. chinensis, $P$. longiductus and $P$. sichuanensis - are incriminated vectors of Chinese VL and a newly found $P$. feng $i$ being considered possibly a potential vector in South China (Leng \& Zhang, 1994).

\begin{tabular}{|c|c|}
\hline 1. Beijing & chinensis (9), mongolensis (7), khawi (5), squamirostris (4) \\
\hline 2. Tianjin & chinensis (6), mongolensis (2), khawi (1), squamirostris (1) \\
\hline 3. Shanghai & chinensis (1) \\
\hline 4. Jilin & chinensis (2) \\
\hline 5. Liaoning & chinensis (33), mongolensis (4), khawi (2), squamirostris (10) \\
\hline 6. Inner Mongolia & chinensis (3), smirnovi (1), alexandri (1), andrejiewi (2), mongolensis (5), sinkiangensis (1) \\
\hline 7. Hebei & chinensis (30), mongolensis (29), khawi (1), squamirostris (11) \\
\hline 8. Shanxi & chinensis (32), mongolensis (18), khawi (12), squamirostris (5), suni (3) \\
\hline 9. Shaanxi & $\begin{array}{l}\text { chinensis (37)*, stantoni (?), kiangsuensis (1), mongolensis (20), khawi (14), nankingensis (?), squamirostris (14), } \\
\text { suni (2), barraudi (?) }\end{array}$ \\
\hline 10. Gansu & $\begin{array}{l}\text { chinensis (33)*, smirnovi (2), alexandri (3), andrejievi (1), mongolensis (22), khawi (5), koloshanensis (1), squa- } \\
\text { mirostris (7), sinkiangensis (1) }\end{array}$ \\
\hline 11. Ningxia & chinensis (5), mongolensis (7) \\
\hline 12. Qinghai & chinensis (7)*, mongolensis (5), squamirostris (2) \\
\hline 13. Xinjiang & $\begin{array}{l}\text { longiductus (28), smirnovi (21), alexandri (13), andrejievi (6), caucasicus (7), mongolensis (24), sumbarica (4), } \\
\text { sinkiangensis (18), sintoni (5), turfanensis (4) }\end{array}$ \\
\hline 14. Shandong & chinensis (91), kiangsuensis (3), mongolensis (64), khawi (9), squamirostris (40) \\
\hline 15. Anhui & $\begin{array}{l}\text { indica (2), chinensis (11), kiangsuensis (12), mongolensis (15), anbuiensis (5), malayensis (1), nankiangensis (2), } \\
\text { squamirostris (14), barraudi (8) }\end{array}$ \\
\hline 16. Jiangsu & chinensis (22), kiangsuensis (12), mongolensis (17), barraudi (1), nankingensis (1), squamirostris (13) \\
\hline 17. Zhejiang & chinensis (2), kiangsuensis (3), mongolensis (1), anbuiensis (1), squamirostris (3), zhongi (2), barraudi (2) \\
\hline 18. Fujian & stantoni (3), quanzhouensis (2), wuyishanensis (2), barraudi (1), yini (2) \\
\hline 19. Taiwan & indica (3), kiangsuensis (1), malayensis (6), barraudi (3) \\
\hline 20. Jiangxi & anbuiensis (1), squamirostris (2), yaoi (1), zhengjiani (2), barraudi (3) \\
\hline 21. Henan & indica (1), chinensis (35), kiangsuensis (4), mongolensis (28), khawi (4), squamirostris (8) \\
\hline 22. Hubei & $\begin{array}{l}\text { chinensis ( (7), kiangsuensis (2), mongolensis (1), anbuensis (1), koloshanensis (2), nankingensis (1), squamirostris } \\
\text { (6), zhengjiani (3), barraudi (3) }\end{array}$ \\
\hline 23. Hunan & longiforceps (1), chinensis (1), tumenensis (1), barraudi (1) \\
\hline 24. Guangdong & $\begin{array}{l}\text { junlianensis (1), indica (2), chinensis (1), stantoni (2), kiangsuensis (4), tumenensis (2), iyengari (1), malayensis } \\
\text { (2), barraudi (1), kwangsiensis (2), bailyi (1), campester (1) }\end{array}$ \\
\hline 25. Hong Kong & indica, barraudi \\
\hline 26. Macao & barraudi \\
\hline 27. Hainan & $\begin{array}{l}\text { indica (3), chinensis (1), stantoni (3), iyengari (1), malayensis (4), barraudi (2), kwangsiensis (2), bailyi (2), cam- } \\
\text { pester (15), fanglianensis (1) }\end{array}$ \\
\hline 28. Guangxi & $\begin{array}{l}\text { junlianensis (2), longiforceps (1), stantoni (1), kiangsuensis (4), lengi (10), tumenensis (1), yunshengensis (2), } \\
\text { anbuiensis (1), koloshanensis (3), barraudi (4), kwangsiensis (2), pooi (1) }\end{array}$ \\
\hline 29. Sichuan & $\begin{array}{l}\text { junlianensis (1), chinensis (17)*, sichuanensis (13), stantoni (2), kiangsuensis (3), tumenensis (8), yunshengensis } \\
\text { (2), koloshanensis (16), squamirostris (9), zhengjiani (6), barraudi (20), yini (1), bailyi (10), campester (2), suni (2) }\end{array}$ \\
\hline 30. Guizhou & $\begin{array}{l}\text { junlianensis (1), longiforceps (1), chinensis (3)*, kiangsuensis (7), tumenensis (1), yunshengensis (1), khawi (1), kolo- } \\
\text { shanensis (3), barraudi (1) }\end{array}$ \\
\hline 31. Yunnam & $\begin{array}{l}\text { longiforceps (5), chinensis (3)*, fengi (1), sichuanensis (1), stantoni (4), kiangsuensis ( } 8 \text { ), lengi ( } 7 \text { ), tumenensis (2), } \\
\text { yunshengensis (1), iyengari (1), khawi (1), koloshanensis (8), kueichenae (1), zhengjiani (3), barraudi (8), rud- } \\
\text { nicki (2), bailyi (2), campester (2), yunnanensis (1) }\end{array}$ \\
\hline 32. Tibet (Xizang) & sicbuanensis (1) \\
\hline
\end{tabular}

()$=$ the number of counties and towns where this fly was collected.

* including the old materials in which some sichuanensis may be mixed in.

Table I. - Phlebotomine sandflies in different provinces, metropolis, autonomous regions and special zones. 
Species

1. C. junlianensis

2. G. indica

3. I. longiforceps

4. P. chinensis

5. P. feng $i$

6. P. longiductus

8. P. stantoni

9. P. kiangsuensis

10. P. lengi

11. P. tumenensis

12. P. yunshengensis

13. P. smirnoti

14. P. alexandri

15. P. andrejievi

16. P. caucasicus

17. P. mongolensis

19. S. iyengari

20. S. khawi

21. S. koloshanensis

22. S. kueichenae

23. S. malayensis

24. S. nankingensis

25. S. quanzhouensis

26. S. squamirostris

27. S. wuyishanensis

28. S. yaoi

29. S. zhengjiani

30. S. zhongi

31. S. barraudi

32. S. kwangsiensis

33. S. rudnicki

35. S. yini

36. S. sinkiangensis

37. S. sintoni

38. S. bailyi

39. S. campester

40. S. fanglianensis

41. S. yunnanensis

42. S. pooi

*43. S. suni

\# 44. S. turfanensis
7. P. sichuanensis

18. S. anhuiensis

34. S. sumbarica

PMAS

C \& T

Guangdong, Guangxi, Guizhou, Sichuan

Anhui, Guangdong, Hainan, Henan, Hong Kong, Taiwan

Guangxi, Guizhou, Henan, Yunnan

Anhui, Beijing, Gansu, Guangdong, Guizhou, Hainan, Hebei, Henan, Hubei, Hunan, Inner

Mongolia, Jiangsu, Jilin, Liaoning, Ningxia, Qinghai, Shaanxi, Shangdong, Shanghai,

Shanxi, Sichuan, Tianjin, Yunnan, Zhejiang

Yunnan

Xinjiang

Sichuan, Tibet, Yunnan

Fujian, Guangdong, Guangxi, Hainan, Shaanxi, Sichuan, Yunnan

Anhui, Guangdong, Guangxi, Guizhou, Henan, Hubei, Jiangsu, Shaanxi, Shangdong,

Sichuan,

Taiwan,Yunnan

Guangxi, Yunnan

Guangdong, Guangxi, Guizhou, Henan, Sichuan, Yunnan

Guangxi, Guizhou, Sichuan, Yunnan

Gansi, Inner Mongolia, Xinjiang

Gansu, Inner Mongolia, Xinjiang

Gansu, Inner Monggolia, Xinjiang

Xinjiang

Anhui, Beijing, Gansu, Hebei, Henan, Hubei, Inner Mongolia, Jiangsu, Kiaoning, Ningxia,

Qinghai, Shaaxi, Shandong, Shanxi,T ianjin, Xinjiang, Zhejiang

Anhui, Hubei, Jiangxi, Guangxi, Zhejiang

Guangdong, Hainan, Yunnan

Beijing, Gansu, Guizhou, Hebei, Henan, Liaoning, Shaanxi, Shandong, Shanxi, Tianjin

Yunnan

Guansu, Guangxi, Guizhou, Hubei, Sichuan, Yunnan

Yunnan

Anhui, Guangdong, Hainan, Taiwan

Anhui, Hubei, Jiangsu, Shaanxi

Fujian

Anhui, Beijing, Gansu, Hebei, Henan, Hubei, Jiangsu, Jiangxi, Liaoning, Qinghai,

Shaanxi, Shandong, Shanghai, Shanxi, Tianjing, Zhejian

Fujian

Jiangxi

Hubei, Jiangxi, Sichuan, Yunnan

Zhejiang

Anhui, Fujian, Guizhou, Guangdong, Guangxi, Hainan, Hong Kong, Hubei, Hunan,

Jiangsu, Jiangxi, Macau, Shaanxi, Sichuan, Taiwan, Yunnan, Zhejiang

Guangdong, Guangxi, Hainan

Yunnan

Xinjiang

Fujian, Sichuan

Gansu, Inner Mongolia, Xinjiang

Xinjiang

Guangdong, Hainan, Sichuan, Yunnan

Guangdong, Hainan, Sichuan, Yunnan

Hainan

Yunnan

Guangxi

Shaanxi, Shanxi, Sichuan

Xinjiang

* may be a synonym of $S$. zhengiani

\# may be a new record of China instead of a new species - S. turfanensis, needs further confirmation. PMAS: Province, Metropolis, Autonomous Region \& Special Zone.

C \& T: County \& Town.

Table II. - Species and distribution. 
4. P. chinensis Newstead, 1916 [392] [24\}

[Newstead, R.: Bull. Ent. Res., 1916, 7(2), 191-192; Nitzulescu, V: Ann. Parasitol. bum. comp., 1931, 9(3), 261-265; Sinton, JA : Ind. J. Med. Res., 1928, 16(2):306-307]

Holotype \& Paratypes: NHML

Distribution: Northeast, Jilin $\left(43.8^{\circ} \mathrm{N}, 126.5^{\circ} \mathrm{E}\right)$, Jilin Province; Northwest, Dunhuang, (40.1 $\left.{ }^{\circ} \mathrm{N}, 94.6^{\circ} \mathrm{E}\right)$, Gansu along Hexi Corridor, the well irrigated part of Old Silk Road; West, Lixian $\left(103.1^{\circ} \mathrm{E}\right)$, Sichuan; Southwest, Hekou $\left(22.4^{\circ} \mathrm{N}, 103.9^{\circ} \mathrm{E}\right)$ and Kunming $\left(25^{\circ} \mathrm{N}, 102.7^{\circ} \mathrm{E}\right)$, Yunnan; Southeast, Nada $\left(19.5^{\circ} \mathrm{N}\right.$, $\left.109.5^{\circ} \mathrm{E}\right)$, Hainan.

$P$. chinensis is the most important vector of $\mathrm{VL}$ and most widely distributed sandfly, but mainly in the north of Changjiang (Yangtze) River and the northeastern quadrant in the lowest flight of the three China's land-steps. The footprints of this fly has been found in 392 towns, counties and cities of 24 provinces, autonomous regions and metropolises.

Line from north to south in the eastern Qinghai, southern Gansu and western Sichuan with its affinity species $P$. sichuanensis.

Anhui: Boxian, Chuxian, Dangshan, Huaiyuan, Linquan, Suixi, Suxian, Taihe, Wuhe, Xiaoxian, Yangshan. (11)

Beijing: Changping, Daxing, Fangshan, Liangxiang, Miyun, Pinggu, Suburb, Tongxian, Yanqing. (9)

Gansu*: Dangchang, Dongxiang, Dunhuang, Gangu, Guanghe, Gaolan, Heshui, Hezheng, Huachi, Huanxian, Jingchuan, Jingyuan, Lanzhou, Lingtai, Linxia, Longxi, Minxian, Ningxian, Pingliang, Qin'an, Qingshui, Qingyang, Tianshui, Tongwei, Wenxian, Wushan, Wudu, Yongdeng, Yongjing, Yuzhong, Zhangye, Zhenning, Zhenyuan. (33)

Guangdong: Lianxian. (1)

Guizhou*: Bijie, Congjiang, Guiyang. (3)

Hainan: Danxian. (1)

Hebei: Anping, Anxin, Baoding, Beidaihe, Chengdong, Dachang, Dingxian, Handan, Laishui, Qianxi, Qinhuangdao, Qinglong, Qingyuan, Qingxian Quzhou, Raoyang, Sanhe, Shanhaiguan, Tangshan, Tangxian, Weixian, Wen'an, Wuji, Wuqiang, Xinglong, Xiongxian, Xushui, Yixian, Zhaoxian, Zunhua. (30)

Henan: Anyang, Bo'ai, Gongxian, Hebi, Huixian, Jixian, Jiyuan, Kaifeng, Lingbao, Linru, Luoning, Luoyang, Lushi, Mianchi, Mengjin, Mengxian, Ningling, Queshan, Qíxian, Qíxian (Chaoge), Sanmenxia, Shaanxian, Shangqiu, Suixian, Taikang, Tangyin, Xin'an, Xinyang, Xingyang, Xiuwu, Xunxian, Yanshi, Yichuan, Yiyang, Yuanyang. (35)

Hubei: Jingmen, Lichuan, Shennongjia, Wudangshan, Xiangyang, Yangxin, Zigui. (7)

Hunan: Huayuan. (1)

Inner Mongolia: Alxa Youqi, Kulunqi, Ningchengxian. (3) Jiangsu: Donghai, Fengxian, Ganyu, Guanyun, Huai'an, Haizhou, Huaiyin, Jiangpu, Lianshui, Lianyungang, Nanjing, Peixian, Pixian, Qingjiang, Sihong, Siyang, Shuyang, Suqian, Tongshan, Xinhailian, Xinyi, Xuzhou. (22)

Jilin: Changchun, Jilin. (2)

Liaoning: Anshan, Beizhen, Benxi, Changhai, Chaoyang, Dalian, Dandong, Donggou, Fengcheng, Fushun, Fuxian,

* Including data of the 1950 's-1960's, some of which are mixed with P. sichuanensis Leng \& Yin, 1983.
Fuxin, Gaiping, Huanren, Jianchang, Jinxi, Jinxian, Harqin Zouqi, Kuandian, Liaoyang, Lingyuan, Lüshun (Port Arthur), Qingyuan, Shenyang, Suizhong, Tieling, Xinbin, Xingcheng, Xinjin, Xiongyue, Xiuyan, Yingkou, Zhuanghe. (33)

Ningxia: Guyuan (Pengyang), Haiyuan, Longde, Xiji, Zhongning. (5)

Qinghai*: Guide, Hualong, Jianzha, Ledu, Minhe, Sining, Xunhua. (7)

Shaanxi*: Baihe, Baishui, Baoji, Binxian, Chang'an, Chengcheng, Dali, Fufeng, Fengxiang, Fuping, Ganquan, Hancheng, Heyang, Huanglong, Huashan, Huayin, Jingyang, Lantian, Meixian, Mizhi, Ningshaan, Qíanxian, Qianyang, Qishan, Sanyuan, Suide, Tongguan, Weinan, Wuqi, Xi'an, Xingping, Xunyi, Yan'an, Yanchang, Yichuan, Yulin, Zichang (Wayaobao). (37)

Shandong: Anqiu, Binxian, Binzhou, Boshan, Boxing, Cangshan, Changle, Changqing, Changshan, Changyi, Dexian, Dezhou, Dingtao, Dongping, Feicheng, Fushan, Gaomi, Guangrao, Guanxian, Haiyang, Heze, Huangxian, Huantai, Huimin, Jiaxiang, Jimi, Jinan, Jining, Jiyang, Juancheng, Juye, Kunyu, Laiyang, Laiwu, Laixi, Leling, Liangshan, Liaocheng, Licheng, Linqu, Linqing, Linyi, Linzi, Muping, Penglai, Pingdu, Pingyin, Pingyuan, Qicun, Qihe, Qixia, Qufu, Rizhao, Rongcheng, Rushan, Shanghe, Shouguan, Shouzhang, Sishui, Tai'an, Tengxian, Tangyi, Weifang, Weihai, Weishan, Weixian, Wendeng, Wudi, Wulian, Wucheng, Xintai, Yanggu, Yangxin, Yanzhou, Yexian, Yidu, Yinan, Yishui, Yixian, Yiyang, Yucheng, Yuncheng, Zanhua, Zhaozhuang, Zhaoyuan, Zhucheng, Zibo, Zichuan, Ziyang, Zouping, Zouxian. (91)

Shanghai: Xuhuiqu. (1)

Shanxi: Daning, Datong, Fanshi, Guangling, Hequ, Hunyuan, Houxian, Jiexiu, Jixian, Kelan, Licheng, Linfen, Lingchuan, Lishi, Liulin, Pingshun, Shilou, Shouyang, Taiyuan, Taigu, Wutai, Wuxiang, Wuzhai, Xiangyuan, Xiaoyi, Xinxian, Yanggao, Yangquan, Yangqu, Yongji, Yuanqu, Yuxian. (32)

Sichuan*: Anxian, Emei, Guanxian, Guangyuan, Heishui, Jinchuan, Junlian, Lixian, Maerkang (Barkam), Maowen, Maoxian, Nanping, Songpan (Sunqu), Wenchuan, Wulong, Xiaojin, Yibin. (17)

Tianjin: Baodi, Jianhai, Jixian, Ninghe, Suburb, Wuqing. (6) Yunnan*: Hekou, Kunming, Shuangjian. (3)

Zhejiang: Changshan, Tiantai. (2) *

5. P. fengi Leng \& Zhang, 1994 [1] \{1\}

[Leng, YJ \& Zhang, LM: Ann. trop. Med. Parasitol., 1994, 88(5):523-530]

$P$. feng $i$ is a newly named Adlerius from Longling County $\left(24.5^{\circ} \mathrm{N}, 98.7^{\circ} \mathrm{E}\right.$, and $900 \mathrm{~m}$ above sea level), Yunnan near to the Sino-Burmese border.

Holotype \& Paratypes: FMJNU

Yunnan: Longling.

An autochthonous case of VL in Liujiang County $\left(24.2^{\circ} \mathrm{N}\right.$, $\left.109.3^{\circ} \mathrm{E}\right)$, Guanxi has been reported. Then, as the other three Chinese Adlerius, it is considered that P. feng $i$ may also be a potential vector of VL in South China (Leng \& Zhang, 1994). 
6. P. longiductus Parrot, 1928 [28] \{1\}

[Parrot, L: Arch. Inst. Pasteur Alger., 1928, 6(1):26-34; Lewis, DJ: Bull. Brit. Mus. (NH), Ent. Ser., 1982, 45(2), 161; Wang, J. et al.: J. Epidemiol., 1966, 4(1):30-32]

Chinese Specimen: SIPD

Distribution: P. longiductus is only found in Xinjiang. North, Tacheng $\left(46.7^{\circ} \mathrm{N}\right)$; East, Hami $\left(93.4^{\circ} \mathrm{E}\right)$; South, Yecheng $\left(37.8^{\circ} \mathrm{N}\right)$; West, Akto $\left(75.9^{\circ} \mathrm{E}\right)$. It opens to west in Afghanistan, India, Pakistan, Romania, Kazakhstan and Uzbekistan.

Xinjiang: Aksu, Akto, Anjihai, Artux, Changji, Emin, Hami, Kalpin, Kashi (Kaxgar), Kuqa, Qitai, Shache, Shanshan, Shufu, Shule, Tacheng, Tekes, Toksun, Turpan, Urumqi, Usu, Wensu, Wushi, Xinyuan, Yecheng, Yining, Yopurga, Yumin. (28)

$P$. longiductus is proved to be a vector of VL in China and Central Asia. The infection rate after experimental feeding is about $54.2 \%$ in Xinjiang (Xiong et al., 1974).

7. P. sichuanensis Leng \& Yin, 1983 [15] \{3\}

[Leng, YJ \& Yin, ZC: Ann. Trop. Med. Parasitol., 1983, 77(4), 423-426]

Holotype \& Paratypes: FMJNU \& NHML

Distribution: North, Nanping $\left(33.2^{\circ} \mathrm{N}\right)$, Sichuan; East, Guangyuan $\left(105.8^{\circ} \mathrm{E}\right)$, Sichuan; South, Huize $\left(26.4^{\circ} \mathrm{N}\right)$, Yunnan; West, Co Nag $\left(92^{\circ} \mathrm{E}\right)$, Tibet. P. sichuanensis is a high mountainous species distributed in the southwest quadrant of the highest flight of three land-steps of China.

Sichuan: Anxian, Guangyuan, Heishui, Jinchuan, Junlian, Lixian, Maerkang (Barkam), Maowen, Nanping, Songpan (Sunqu), Wenchuan, Xiaojin, Yibin. (13)

Xizang (Tibet): Co Nag (Cona, Lexiang). (1)

Yunnan: Huize. (1)

P. sichuanensis is the only PS found in Tibet and being incriminated a vector of VL in Northwest Sichuan with an artificial infection rate of $60.8 \%$ for local Leishmania (Yin, Leng et al., 1985) and probably a vector in southern Gansu and eastern Qinghai.

The old surveying material of $P$. chinensis included in this paper from Gansu, Guizhou, Qinghai and Yunnan and some from Sichuan may be mixed with $P$. sichuanensis which has been named after those surveys

$P$. sichuanensis and $P$. chinensis have been well studied comparatively with life-history, hybridization analysis, isozyme characterization, morphostructural and morphometric characteristics, geographical distribution and relation to disease transmission (Leng \& Zhang, 1992). These two flies are isolated species

\section{b. Subgenus Anaphlebotomus Theodor, 1948}

[Theodor, O: 1948:3(1):99, 1958:19; Lewis, DJ: 1982:171-172]

\section{P. stantoni Newstead, 1914 [15] \{7\}}

[Newstead, R: Bull. Ent. Res., 1914, 5:179-192; Raynal, J \& Gaschen H: Bull. Soc. Path. Exot., 1934b, 27:(7):670-675; Leng, YJ \& Zhang, LM: Ann. Trop. Med. Parasitol., 1993, 87(1):89]

It is the only one species of Anapblebotomus - P. stantoni confirmed in China after $P$. hoepplii was synonymized by Lewis (1987)
Synonym: P. hoepplii Tang \& Maa, 1945

[Tang \& Maa: Res. Bull. Fukien Acad., 1945, 1:241-245. Male and female, holotype male]

Chinese Specimen: FMJNU \& SIPD

Distribution: North, Nanping $\left(29.1^{\circ} \mathrm{N}\right)$, Sichuan; East, Jianyang $\left(118.1^{\circ} \mathrm{E}\right)$, Fujian; South, Yaxian $\left(18.2^{\circ} \mathrm{N}\right)$, Hainan; West, Luxi (Mangshi, $98.5^{\circ} \mathrm{E}$ ), Yunnan covering 15 towns and counties of one autonomous region and 3 provinces in South - and Southwest China. In the south it opens to Indian Subcontinent including Sri Lanka and Southeast Asian countries - West Malaysia, Thailand, Laos, Vietnam and Indonesia (Java).

Fujian: Jianyang, Shaowu, Yongan. (3)

Guangdong: Guangzhou, Zhanjiang. (2)

Guangxi: Lingyun. (1)

Hainan: Baoting, Wenchang, Yaxian. (3)

Shaanxi: county unknown.

Sichuan: Junlian, Nanping. (2)

Yunnan: Luxi (Mangshi), Menglian, Simao, Yuanjiang. (4).

\section{c. Subgenus Euphlebotomus Theodor, 1948}

[Theodor, O: 1948:89-99]

Four species are treated belonging to Euphlebotomus. They are all cave dwellers where rodents, bats and birds are the common inhabitants. The author had been actively attacked by $P$. kiangsuensis and $P$. yunshengensis in limestone caves for many times with severe itching. The discovered Chinese Euphlebotomus are all in the south of Changjiang River and except $P$. kiangsuensis the other three are distributed mainly in the South and Southwest mountainous area.

Taxonomy: Leng \& Lewis (1987) stated that in the subgenus Euphlebotomus, P. tumenensis and P. yunshengensis are the only species with a negative $p i$ in venation and with the distal segment of the spermatheca bulbous and longer than the rest combined. The wing shape and venation (negative $p i$ and positive delta) of $P$. yunshengensis are rather similar to those of the Afrotropical subgenus Spelaeophlebotomus Theodor, 1948. In the former, however, the distance between the base of R4 and R5 (gamma, longer than quarter of wing width, 1/1.7), the spatulate sensilla on palpal segment 3 , the long proboscis, A3/L less than 2 (1.7) and the genital pump without adjacent chitinous rods are remarkably different from Spelaeophlebotomus. Chinese species of Euphlebotomus with trilobed parameres and the aedeagus without accessory spines. But the trilobed parameres of $P$. lengi are vestigial. It seems that two Chinese members, $P$. tumenensis and $P$. yunshengensis treated in subgenus "Euphlebotomus ", should be arranged in a new subgenus.

9. P. kiangsuensis Yao \& Wu, 1938 [64] \{13\}

[Yao, YT \& Wu, CC: Chn. med. J. (Suppl. 2), 1938:527-537]

Holotype \& Paratypes: SIPD

Distribution: North, Tengxian, $\left(35.1^{\circ} \mathrm{N}\right)$, Shandong; East, Taidong $\left(121.1^{\circ} \mathrm{E}\right)$, Taiwan; West, Baihe $\left(110^{\circ} \mathrm{E}\right)$, Shaanxi; Southwest, Yingjiang $\left(26.4^{\circ} \mathrm{N}, 97.9^{\circ} \mathrm{E}\right)$ and Mengla $\left(21.4^{\circ} \mathrm{N}\right.$, $101.5^{\circ} \mathrm{E}$ ), Yunnan. P. kiangsuensis is one common phlebotomine in the south of Huanghe River covering 64 counties and cities of 13 provinces and autonomous regions. Anhui: Boxian, Funan, Fuyang, Guoyang, Huaiyuan, Linquan, Mengcheng, Sucheng, Suixi, Taihe, Wuhe, Yingshang. (12) 
Guangdong: Lianxian, Qujiang, Yangshan, Yingde. (4)

Guangxi: Debao, Fuchuan, Jingxi, Lingyun. (4)

Guizhou: Bijie, Ceheng, Congjiang, Liping, Longli, Qinglong, Tongren. (7)

Henan: Gongxian (Xiaoyi), Kaifeng, Shangqiu, Xinyang. (4) Hubei: Jingmen, Xiangyang. (2)

Jiangsu: Donghai, Ganyu, Huai'an, Huaiyin, Jiangpu, Lianshui, Nanjing, Peixian, Pixian, Xinyi, Xuzhou, Yangzhou. (12) Shaanxi: Baihe. (1)

Shandong: Linyi, Tengxian, Weishan. (3)

Sichuan: Junlian, Maowen, Wulong. (3)

Taiwan: Taidong. (1)

Yunnan: Jinggu, Longling, Lùxi, Mengla, Simao, Wenshan, Yanjin, Yingjiang. (8)

Zhejiang: Deqing, Yuhang, Zhoushan. (3)

10. P. lengi Zhang, He \& Ward, 1994 [8] \{2\}

[Zhang, LM, He, MS \& Ward, RD: Ann. Trop. Med. Parasitol., 1994, 88(5):531-537]

\section{Holotype \& Paratypes: FMJNU}

Distribution: North, Lùxi $\left(24.5^{\circ} \mathrm{N}\right)$, Yunnan; East Lingyun $\left(106.5^{\circ} \mathrm{E}\right)$, Guangxi; South, Mengla $\left(21.4^{\circ} \mathrm{N}\right)$, Yunnan; West, Menglian $\left(99.5^{\circ} \mathrm{E}\right)$, Yunnan. $P$. lengi is distributed in subtropical rain forest of high mountainous area covering 7 counties in Yunnan and one in Guangxi.

Guangxi: Lingyun. (1)

Yunnan: Funing, Jinggu, Mengla, Menglian, Lùxi, Simao, Yongde. (7)

11. P. tumenensis Wang \& Chang, 1963 [15] \{6\}

[Wang, CT \& Chang, YS: Acta Entomol. Sin., 1963, 12(4):511514]

Holotype \& Paratypes: SDIPD

Distribution: North Maowen $\left(31.6^{\circ} \mathrm{N}\right)$, northern Sichuan; East, Yangshan $\left(112.6^{\circ} \mathrm{E}\right)$ Guangdong; Southwest, Mengla $\left(21.4^{\circ} \mathrm{N}\right.$, $101.5^{\circ} \mathrm{E}$ ), Yunnan covering 15 counties in one autonomous region and 5 provinces.

Guangdong: Lianxian, Yangshan. (2)

Guangxi: Lingyun. (1)

Guizhou: Congjiang. (1)

Hunan: Lingling. (1)

Sichuan: Emei, Gaoxian, Junlian, Maowen, Pingshan, Rongxian, Wenchuan, Yibin. (8)

Yunnan: Funing, Mengla. (2)

12. P. yunsbengensis Leng \& Lewis, 1987 [6] \{4\} [Leng, YJ \& Lewis DJ: Ann. Trop. Med. Parasitol., 1987, 8(3):305-309]

Holotype \& Paratypes: FMJNU \& NHML

Distribution: North, Rongxian $\left(29.4^{\circ} \mathrm{N}, 104.4^{\circ} \mathrm{E}\right)$, Sichuan; East, Fuchuan $\left(111.2^{\circ} \mathrm{E}\right)$, Guangxi; Southwest, Mengla $\left(21.4^{\circ} \mathrm{N}, 101.5^{\circ} \mathrm{E}\right)$, Yunnan covering 6 counties in one autonomous region and 3 provinces.

Guangxi: Fuchuan, Lingyun. (2)

Guizhou: Congjiang. (1)

Sichuan: Junlian, Rongxian. (2)

Yunnan: Mengla. (1)

\section{d. Subgenus Larroussius Nitzulescu, 1931}

[Nitzulescu, V: Ann. Parasitol. hum. comp., 1931a, 9(3):271275]
Only one species of Larroussius is found in China, P. smirnovi, which has been proved a vector of Chinese VL.

13. P. smirnovi Perfiliew, 1941 [24] \{3\}

[Perfiliew, PP: Trudy Voenno-Meditsinskoe Akademii im. SM Kirova, 1941, 25:272-284; Lewis, DJ, 1982:162-163]

Synonym :

1. P. major Ting \& Ho, 1962 [Ting, ST \& Ho, KT: Acta Entomol. Sin., 1962, 11(4):388-393]

2. P. major wui Yang \& Xiong, 1965 [Yang, KY \& Xiong, GH: Acta Parasitol. Sin., 1965, 2(4):412-415]

3. P. wui Artemiev \& Neronov, 1984 [Artemiev, MM \& Neronov VM: 1984:103-105; Xiong, GH \& Jin CF: Chn. J. Prasitol. parasit. Dis., 1987, 5(1):45-47]

Synonymized by Leng, Lane and Lewis [Leng YJ, Lane, RP \& Lewis, DJ: Ann. Bull. Soc. Parasitol., Guangdong Province, 1987, 8/9:40-43].

Chinese Specimen: FMJNU, \& DIPD

Distribution: North, Tacheng $\left(46.7^{\circ} \mathrm{N}\right)$, Xinjiang; East, Ejin Qi $\left(101^{\circ} \mathrm{E}\right)$, Inner Mongolia; Southwest, Akto $\left(39.1^{\circ} \mathrm{N}, 75.9^{\circ} \mathrm{E}\right)$, Xinjiang, mainly in the desert, semidesert and grassland from Xinjiang to Inner Mongolia north of Kara-Kunlun Mountains and Hexi Corridor where separates $P$. smirnovi from Tibet and the well irrigated parts of Gansu. It covers 24 counties and banners $(q i)$ in one province and two autonomous regions. But in the north it opens to Mongolia and in the west to Kazakhstan, Central Asia.

Gansu: Anxi, Dunhuang. (2)

Inner Mongolia: Ejin Qi. (1)

Xinjiang: Akto, Aksu, Artux, Bachu, Hami, Karamay, Kashi (Kaxgar), Keping, Kuqa, Mosuowan, Shanshan, Shayar, Shufu, Shule, Tacheng, Tarim Basin (Upper and Middle Basin-desert), Toksun, Usu, Wensu, Yining, Yupurga. (21) P. smirnovi was found naturally infected (2.9\%) with Leishmania during the sandfly season in Xinjiang epidemic area.

\section{e. Subgenus Paraphlebotomus Theodor, 1948}

[Theodor, O, 1948:97; 1958:19, Lewis, DJ, 1982:143]

Four species are belonging to Paraphlebotomus. Three of them, $P$. alexandri, $P$. andrejievi and $P$. caucasicus are desert, semi-desert and grassland inhabitants.

14. P. alexandri Sinton, 1928 [17] \{3\}

[Sinton, JA: Ind. J. Med. Res., 1928, 16(2):308; Xiong, GH, Wang J., et al.: Acta Entomol. Sin., 1963, 12(4):458-462; Hsiong, KH, Wang, J. \& Kuan, LR: Acta Entomol. Sin., 1964, 13(1):141-144]

Chinese Specimen: SIPD

Distribution: North, Jinghe $\left(44.6^{\circ} \mathrm{N}\right)$, Xinjiang; East, Alxa Youqi $\left(101.7^{\circ} \mathrm{E}\right)$, Inner mongolia; Southwest, Shufu $\left(39.4^{\circ} \mathrm{N}\right.$, $75.8^{\circ} \mathrm{E}$ ), Xinjiang. P. alexandri is reported with a wide distribution from Morocco, Northwest Africa and Spain, West Europe via East Europe and Middle East to Central Asia and China, butwith many morphological variations.

$P$. alexandri is proved to be a vector of VL in China with a natural Leishmania infection rate of $2.0 \%$ and it has been found on the northern slope of Qilian Mountain Range at about $3,200 \mathrm{~m}$ above sea level $\left(39^{\circ} \mathrm{N}, 98^{\circ} \mathrm{E}\right)$ near Jiayuguan $\left(39.8^{\circ} \mathrm{N}, 98.2^{\circ} \mathrm{E}\right)$ in Gansu (Leng \& Zhang, 1991), where probably is the highest living site for PS in the world. 
Gansu: Dunhuang, Jiuquan (Heishanhu), Jiayuguan (on the northern slope of Qilianshan Mountain Range near Jiayuguan at 3,200 $\mathrm{m}$ above sea level) (3)

Inner Mongolia: Alxa Youqi (in the caves on south slope of Mt. Yablait). (1)

Xinjiang; Artux, Aksu, Jinghe, Kashi (Kaxgar), Kuqa, Shawan, Shayar, Shufu, Turpan Basin, Wensu, Wusu, Yiwu. (13)

15. P. andrejievi Shakirzyanova, 1953 [9] \{3\} [Shakirzyanova, MS: Trudy Instituta Zoologi Akademi Nauk Kazakbskoe SSR. 1953, 1:102-107; Guan, LR et al.: Acta Entomotax. Sin., 1981, 3(7):28]

Chinese Specimen: SIPD

Distribution: North, Karamay $\left(45.6^{\circ} \mathrm{N}\right)$, Xinjiang; Southeast, Wulate Houqi (Oog Ondor, $\left.41.4^{\circ} \mathrm{N}, 107^{\circ} \mathrm{E}\right)$, Inner Mongolia; West, Huocheng $\left(80.4^{\circ} \mathrm{E}\right)$, Xinjiang covering 7 counties and 2 banners in one province and two autonomous regions. $P$. andrejievi is also in Afghanistan, Mongolia, Kazakhstan and Uzbekistan and is suspected a vector of Le. major (gerbilli?) in Central Asian countries (Sergiev, 1979). And is a vector of Le. turanica and Le. gerbilli of great gerbil (Rhombomys optimus) in North Xinjiang, China on the basis of natural infection (13.1\%) and experimental transmission (Guan et al., 1994).

Gansu: Minqin. (1)

Inner Mongolia: Ejin Qi, Wulate Houqi. (2)

Xinjiang: Bole, Fukang, Huocheng, Karamay, Mesuowan, Qitai. (6)

16. P. caucasicus Marzinovsky, 1917 [7] \{1\}

[Marzinowsky, E: Meditsinskoe Obozerenie, 1917, 87(13/16)611-614; Xiong, GH et al.: Acta Entomol. Sin., 1964, 13(1):141144]

Chinese Specimen: SIPD

Distribution: Only in Xinjiang. North, Tacheng $\left(46.7^{\circ} \mathrm{N}\right)$, Southwest, Urumqi $\left(43.8^{\circ} \mathrm{N}, 87.6^{\circ} \mathrm{E}\right)$; West, Huocheng $\left(80.8^{\circ} \mathrm{E}\right)$. $P$. caucasicus is also in Afghanistan, Armenia, Azerbaydzhan, Georgia, Kazakhstan and Uzbekistan.

Xinjiang: Emin, Huocheng, Jinghe, Karamay, Tacheng, Urumqi, Yili. (7)

It is considered a vector of VL in Kazakhstan (Sergiev, 1979) and suspected a vector of Le. major (gerbilli?) among rodents in Central Asia (Killick-Kendrick, 1990).

17. P. mongolensis Sinton, 1928 [269] \{17\}

[Sinton, JA: Ind. J. Med. Res., 1928, 16(2):309]

Chinese Specimen: FMJNU \& SIPD

Distribution: North, Tacheng (Qoqek, $46.7^{\circ} \mathrm{N}$ ), Xinjiang; East, Gaixian $\left(122.3^{\circ} \mathrm{E}\right)$, Liaoning; South, Huzhou $\left(30.8^{\circ} \mathrm{N}\right)$, Zhejiang and in the West opens to Afghanistan, Azerbaydzhan, Kazakhstan and Uzbekistan, Central Asia. P. mongolensis is a common species spreading in the north of Changiiang River covering 269 towns, counties and cities in 17 provinces, autonomous regions and metropolises. With exception of only one county (Huzhou, $30.8^{\circ} \mathrm{N}, 120.1^{\circ} \mathrm{E}$ ) near the south bank of Changjiang River.

Anhui: Bengbu, Boxian, Dangshan, Fengtai, Guoyang, Huaiyuan, Linquan, Mengcheng, Sixian, Suixi, Suxian, Wuhe, Xiaoxian, Yangshan, Yinshang. (15)

Beijing: Daxing, Changping, Liangxiang, Miyun, Suburb, Tongxian, Yanqing. (7)
Gansu: Anxi, Dongxiang, Dunhuang, Gaolan, Huanxian, Jianyuguan, Jingchuan, Jingyuan, Jinta, Jiuquan (Heishanhu), Lanzhou, Lingtai, Linxia, Minqin, Shandan, Tianshui, Wushan, Wuwei, Zhangye, Zhenyuan, Yongdeng, Yongjing. (22)

Hebei: Anxian, Andong, Anping, Baoding, Dachang, Gaocheng, Guantao, Handan, Huolu, Jinxian, Laishui, Qianxi, Qinglong, Qingyuan, Quzhou, Raoyang, Shahe, Tangxian, Weixian, Wen'an, Wuji, Wuqiang, Xinglong, Xiongxian, Xushui, Yixian, Zaoqiang, Zhaoxian, Zunhua. (29)

Henan: Biyang, Changyuan, Gongxian, Huixian, Huojia, Kaifeng, Lingbao, Linru, Luoyang, Lushi, Mianchi, Mengjin, Mengxian, Ningling, Puyang, Qixian, Shangqiu, Suixian, Taikang, Tangyin, Wenxian, Xin'an, Xunxian, Yanshi, Yiyang, Yichuan, Yuanyang, Zhongmou. (28)

Hubei: Jingmen. (1)

Inner Mogolia: Alxa Youqi, Ejin Qi, Linhexian, Urad Houqi, Jungger Qi. (5)

Jiangsu: Donghai, Fengxian, Ganyu, Huai'an, Huaiyin, Jiangpu, Lianshui, Peixian, Pixian, Shuyang, Suining, Sihong, Siyang, Suqian, Tongshan, Xinyi, Xuzhou. (17)

Liaoning: Gaixian, Jinzhou, Suizhong, Xingcheng. (4)

Ningxia: Guyuan, Helan, Ningxia, Shizhuishan, Wuzhong, Yinchuan, Zhongning. (7)

Qinghai: Ledu, Hualong, Minhe, Xining, Xunhua. (5)

Shaanxi: Baishui, Binxian, Dali, Dingbian, Chengcheng, Fuping, Huanglong, Hancheng, Huayin, Mizhi, Pucheng, Sanyuan, Suide, Weinan, Wuqi, Xi'an, Xinping, Yanchang, Yichuan, Yulin. (20)

Shandong: Binxian, Boxing, Changqing, Changyi, Chiping, Dexian, Dezhou, Dingtao, Dongping, Feicheng, Gaomi, Gaotang, Guangrao, Guanxian, Heze, Huantai, Huimin, Jiaxiang, Jinan, Jining, Jiningshi, Jinxiang, Jiyang, Juancheng, Juye, Leling, Liangshan, Liaocheng, Licheng, Lijin, Linqing, Linyi, Linzi, Ningjin, Penglai, Pingdu, Pingyin, Pingyuan, Qidong, Qihe, Qingyun, Shanghe, Shouguang, Shouzhang, Tai'an, Tangyi, Tengxian, Weifang, Weishan, Weixian, Wenshang, Wucheng, Wudi, Xiajin, Yanggu, Yanzhou, Yucheng, Zaozhuang, Zhanhua, Zibo, Ziyang, Zouping, Yangxin, Yidu. (64)

Shanxi: Daning, Fanchi, Jiexiu, Jixian, Hequ, Huoxian, Linfen, Lishi, Liulin, Shanyin, Shilou, Taiyuan, Wuxiang, Wuzhai, Xiaoyi, Xinxian, Yangqu, Yongji. (18)

Tianjin: Jinghai, Suburb. (2)

Xinjiang: Akto, Artux, Bole, Changji, Emin, Fukang, Hami, Hoxtologay, Huocheng, Jinghe, Karamay, Kashi (Kaxgar), Mesuowan, Qitai, Shanshan, Tacheng, Toksun, Turpan, Urumqi, Wushi, Usu, Yecheng, Yining, Yumin. (24)

Zhejiang: Huzhou (Wuxing). (1)

$P$. mongolensis is a vector of rodents leishmaniasis caused by Leishmania gerbilli in Turkmenistan (Saf janova, 1967) and in Mongolia (Killick-Kendrick, 1990) on the basis of ecology and natural infection. Natural infection of Leishmania gerbilli has been found both in gerbil (Rhombomys optimus) and P. alexandri and P. mongolensis (Wang et al., 1964) and in P. caucasicus, and P. mongolensis (Xiong et al., 1964; Guan et al., 1994) and in $P$. andrejevi in North Xinjiang, China. These PS are considered to be vectors based upon experimental transmission and natural infection. 
E. Genus Sergentomyia franca \& Parrot, 1920

[Franca, C \& Parrot, L: Bull. Soc. Path. Exot., 1920, 13(8):695-708]

\section{f. Subgenus Neopblebotomus Franca \& Parrot, 1920}

[Theodor, O, 1948:101-102, 1958:33,48; Lewis, DJ, Bull. Brit. Mus. (NH), Ent. Ser., 1978, 37(6):269-270]

It is a common subgenus in Oriental Region and the Far East and 12 species have been identified in China. Nine of them - anbuiensis, iyengari, koloshanensis, malayensis, quanzbouensis, wuyishanensis, yaoi, zhengjiani and zhongi-are mainly distibuted in the south of Changjiang River. Three of them - khawi, nankiangensis and squamirostris - are Palaearctic members and distributed in the north of Changjiang River.

18. S. anbuiensis Ge \& Leng, 1990 [9] \{5\}

[Ge, NL \& Leng, YJ : Contr. Blood-sucking dipt. Ins., 1990, 2:110-116]

Holotype \& Paratypes: FMJNU

Distribution: North, Yuexi $\left(30.8^{\circ} \mathrm{N}\right)$, Anhui; East Jingxian $\left(.4^{\circ} \mathrm{E}\right)$, Anhui; Southwest at Lingyun $\left(24.3^{\circ} \mathrm{N}, 106.5^{\circ} \mathrm{E}\right)$, Guangxi covering 9 counties in 4 provinces and one autonomous region.

Anhui: Jingxian, Qianshan, Qimen, Shitai, Yuexi. (5)

Hubei: Yangxin. (1)

Jianhxi: Pengze. (1)

Guangxi: Lingyun. (1)

Zhejiang: Jiangde. (1)

19. S. iyengari Sinton, 1933 [3] \{3\}

[Sinton, JA: Ind. J. Med. Res., 1933, 21(1):221-224; Raynal, J \& Gaschen H.: Bull. Soc. Path. Exot., 1935a, 1935b, 28(6):507517, 582-592; Leng, YJ: Acta Entomol. Sin., 1977, 20(3):331336]

Chinese Specimen: FMJNU

Distribution: Northeast, Zhanjiang $\left(21.2^{\circ} \mathrm{N}, 110.3^{\circ} \mathrm{E}\right)$, Guangdpong; South, Danxian $\left(19.5^{\circ} \mathrm{N}\right)$, Hainan; West, Mengla $\left(101.5^{\circ} \mathrm{E}\right)$,Yunnan. S. iyengari is also noted in India, Laos, Malaysia, Thailand and Vietnam.

Guangdong: Zhanjiang. (1)

Hainan: Danxian. (1)

Yunnan: Mengla. (1)

20. S. kbawi Raynal, 1936 [55] \{11\}

[Raynal, J: Ann. Parasit. bum. comp., 1936, 16(6):529-540]

$S$. khawi is a common Chinese Palaearctic member and the type comes from the vicinity of Beijing.

Chinese Specimen: FMJNU

Distribution: North, Xingcheng $\left(40.6^{\circ} \mathrm{N}\right)$, Liaoning; East, to sea; West, Wenxian $\left(104.6^{\circ} \mathrm{E}\right)$, Gansu; South to Changjiang River at about $30^{\circ} \mathrm{N}$ except two counties each in North Guizhou and Yunnan of the Southwest Mountainous Area up to about $28^{\circ} \mathrm{N}$ and at about $105^{\circ} \mathrm{E}$ from West as it in the north of Changjiang River. This fly is also noted in Cambodia and Malaysia (Seccombe, Ready \& Huddleston, 1993).

In China it seems that $105^{\circ} \mathrm{E}$ is the west and $28^{\circ} \mathrm{N}$ the south border for Chinese $S$. squamirostris and S. khawi.

Beijing: Changping, Liangxiang, Miyun, Suburb, Yanqing. (5)
Gansu: Jingchuan, Lingtai, Ningxian, Wenxian, Zhengning.(5) Guizhou: Bijie. (1)

Hebei: Xinglong. (1)

Henan: Kaifeng, Gongxian, Xinyang, Xingyang. (4)

Liaoning: Suizhong, Xingcheng. (2)

Shaanxi: Baoji, Chang'an, Chencheng, Fengxian, Jingyang, Hancheng, Huanglong, Meixian, Qishan, Xi'an, Weinan, Xunyi, Yanchang, Yichuan. (14)

Shandong: Boshan, Jinan, Kunyu, Laiyang, Rushan, Tai'an, Wendeng, Zibo, Zouping. (9)

Shanxi: Daning, Jixian, Licheng, Lingchuan, Linfen, Liulin, Pingshun, Taiyuan, Xiangyuan, Xiaoyi, Yongji, Yuxian. (12) Tianjin: Suburb. (1)

Yunnan: Weixin. (1)

21. S. koloshanensis Yao \& Wu, 1946 [33] \{6\}

[Yao, YT \& Wu, CC: J. Parasitol., 1946, 32:87-90]

Holotype \& Paratypes: SIPD

Distribution: North, Wenxian $\left(33.0^{\circ} \mathrm{N}\right)$, Gansu; East, Yichang $\left(111.2^{\circ} \mathrm{E}\right)$, Hubei; South, Jingxi $\left(23.1^{\circ} \mathrm{N}\right)$, Guanxi; West, Maowen $\left(103.8^{\circ} \mathrm{E}\right)$, Sichuan; covering 33 counties and cities in 5 provinces and one autonomous region.

Gansu: Wenxian. (1)

Guangxi: Debao, Jingxi, Lingyun. (3)

Guizhou: Chongjian, Ceheng, Qinglong. (3)

Hubei: Wudangshan, Yichang. (2)

Sichuan: Changning, Chongqing, Emei, Gaoxian, Gongxian, Guangyuan, Jiang'an, Junlian, Leshan, Maowen, Nanping, Rongxian, Wenchuan, Wulong, Xingwen, Zigong. (16)

Yunnan: Lúxi, Lùxi, Mengla, Menglian, Shidian, Weixin, Yanjin, Yongde. (8)

22. S. kueicbenae Leng \& He, 1995 [1] \{1\}

[Leng, YJ \& He, MS: Entomologia Sinica, 2(1):13-17]

Holotype \& Paratypes: FMJNU

Distribution: Mengyuan Cave, Mengla County, $21^{\circ} 24^{\prime} \mathrm{N}$, 101³0', Yunnan Province. A limestone cave dweller. Yunnan: Mengla (1)

23. S. malayensis (Theodor, 1938) Leng \& Zhang, 1991 [13] \{4\}

[Leng, YJ \& Zhang, LM: Contr. Blood-sucking dipt. Ins., 1991, 3:93; Leng \& Zhang: Ann. Trop. Med. Parasitol., 1993, 87(1):91]

Synomyms:

1. P. iyengari malayensis Theodor, 1938

[Theodor, O: Ind. J. Med. Res., 1938, 26(1):261-269]

2. Pblebotomus iyengari hainensis Yao \& Wu, 1938

[Yao, YT \& Wu CC: Trans. 10t Congr. FEATM, 1938a, 2:786790]

3. P. iyengari taiwanensis Cates \& Lien, 1970

[Cates, MD \& Lien, JC: J. Med. Ent., 1970, 7(5):530-533]

4. S. hainanensis Leng, 1977

[Leng, YJ: Acta Entomol. Sin., 1977, 20(3):331-336; Ge, NL: Postgraduate J. Jinan. Univ., 1988, 4(2):104-110].

S. hainanensis (Leng, 1977; Ge, 1988) had been used as the valid name for malayensis Theodor, 1938. But Theodor's paper was published earlier (July) than that of Yao \& Wu's (December) though both in 1938. According to ICZN Article 23, Leng $(1977,1988)$ treated S. malayensis a valid 
name instead of $S$. hainanensis and hainanensis and taiwanensis are synonyms of it.

Chinese Specimen: FMJNU

Distribution: North, Huoqiu $\left(32.2^{\circ} \mathrm{N}\right)$, Anhui; East, Yilan $\left(121.7^{\circ} \mathrm{E}\right)$, Taiwan; South, Lingshui $\left(18.4^{\circ} \mathrm{N}\right)$, Hainan; West, Danxian $\left(109.5^{\circ} \mathrm{E}\right)$, Hainan covering 13 counties in 4 provinces.

Anhui: Huoqiu. (1)

Guangdong: Shixing, Zhanjiang. (2)

Hainan; Baoting, Danxian (Nanfeng), Lingshui, Nada. (4) Taiwan: Gaoxiong, Hualian, Pingdong, Taibei, Taidong, Yilan. (6)

24. S. nankingensis Ho, Tan, Chen \& Wu, 1954 [4] $\{4\}$

[Ho, KT, Tan, CC, Chen, DH \& Wu, CC: Acta Entomol. Sin., 1954, 4:427-432]

Holotype \& Paratypes: SIPD

Distribution: North, Xiangyang $\left(32^{\circ} \mathrm{N}\right)$, Hubei; East, Nanjing $\left.\left(118.7^{\circ} \mathrm{E}, 32^{\circ} \mathrm{N}\right)\right)$, Jiangsu; South, Jinzhai $\left(31.6^{\circ} \mathrm{N}\right)$, Anhui; West, Shaanxi $\left(109^{\circ} \mathrm{E}\right)$. It seems to distribute in a narrow zone around about $32^{\circ} \mathrm{N}$.

Anhui: Jinzhai, Qianshan. (2)

Hubei: Xiangyang. (1)

Jiangsu: Nanjing. (1)

Shaaxi: County unknown.

25. S. quanzbouensis Leng \& Zhang, 1987 [2] \{1\}

[Leng, YJ, Zhang, LM: Acta Zootax. Sin., 1987, 12(2):192-199]

Holotype \& Paratypes: FMJNU

Fujian: Quanzhou $24.8^{\circ} \mathrm{N}, 118.5^{\circ} \mathrm{E}$ ) and Xiamen (Amoy, $\left.24.4^{\circ} \mathrm{N}, 118.1^{\circ} \mathrm{E}\right)$. (2)

26. S. squamirostris Newstead, 1923 [141] \{16\}

[Newstead, R: Ann. Trop. Med. Parasitol., 1923, 17(4):531532]

Type: LSTM, Chinese Specimen: FMJNU, SIPD

Distribution: The type of $S$. squamirostris was discovered in Japan, however being a Palaearctic member and the most common Sergentomyia from Liaohe River Plain of Liaoning in the north via North China Plain southwards to Changjiang River. Its north border at Lingyuan $\left(41,2^{\circ} \mathrm{N}, 119.3^{\circ} \mathrm{E}\right)$ and Benxi $\left(41.3^{\circ} \mathrm{N}, 124.1^{\circ} \mathrm{E}\right)$, Liaoning, the south in Yandang Mountain Range $\left(28.0^{\circ} \mathrm{N}, 120.5^{\circ} \mathrm{E}\right)$, Zhejiang, the West at Wenxian $\left(31^{\circ} \mathrm{N}, 104.9^{\circ} \mathrm{E}\right)$, southern Gansu and the east to sea. It covers 141 towns, counties and cities of 3 metropolises and 13 provinces. Among them are two cities and one county at the south bank and three counties in the south of Changiiang River.

Anhui: Boxian, Bengbu, Chuzhou, Fengtai, Guoyang, Jinzhai, Huaiyuan, Huangshan, Linquan, Mengcheng, Suixi, Taihe, Wuhe, Xiaoxian. (14)

Beijing: Liangxiang, Suburb, Tongxian, Yanqing. (4)

Gansu: Gangu, Jingchuan, Lingtai, Ningxian, Tianshui, Wenxian, Zhenyuan. (7)

Hebei: Dachang, Dingxian, Handan, Laishui, Qianxi, Qinglong, Sanhe, Xinglong, Xushui, Yixian, Zunhua. (11)

Henan: Gongxian, Kaifeng, Lingbao, Queshan, Tangyin, Xinyang, Xingyang, Yanshi. (8)
Hubei: Fancheng, Hong'an, Jingmen, Shennongjia, Yicheng, Xiangyang. (6)

Jiangsu: Donghai, Ganyu, Huai'an, Huaiyin, Jiangpu, Lianyungang, Nanjing, Peixian, Pixian, Tongshan, Xinyi, Xuzhou, Yangzhou. (13)

Jiangxi: Jiujiang, Pengze. (2)

Liaoning: Anshan, Benxi, Dalian, Fengcheng, Jianchang, Jinxi, Lüshun (Port Arthur), Suizhong, Xingcheng, Xiuyan. (10)

Qinghai: Guanting, Minhe. (2)

Shaanxi: Baoji, Chang'an, Fengxiang, Huanglong, Huayin, Jingyang, Lantian, Meixian, Ningshaan, Qishan, Xi'an, Xianyang, Yanchang, Yichuan. (14)

Shandong: Anqiu, Boshan, Cangshan, Changqing, Dezhou, Feicheng, Gaomi, Haiyang, Heze, Jimi, Jinan, Jining, Jiyang, Kunyu, Laixi, Leling, Liangshan, Licheng, Linqu, Linyi, Linzi, Pingdu, Qingdao, Qixia, Rushan, Shouguang, Tai'an, Weifang, Weihai, Wendeng, Wulian, Yanzhou, Yexian, Yidu, Yishui, Yixian, Zhaoyuan, Zhucheng, Zouping, Zouxian. (40)

Shanghai: Xuhuiqu. (1)

Shanxi: Jixian, Linfen, Lingchuan, Taiyuan, Yongji. (5)

Tianjin: Suburb. (1)

Zhejiang: Deqing (Moganshan), Jiande, Leqing (North Yandangshan). (3)

S. squamirostris is recorded as a vector of Trypanosoma bocagei, a parasite of toads, in China (Adler \& Theodor, 1957).

27. S. wuyisbanensis Leng \& Zhang, 1987 [2] \{1\} [Leng, YJ \& Zhang, LM: Acta Zootax. Sin., 1987, 12(2):192199]

Holotype \& Paratypes: FMJNU

Fujian: Chong'an $\left(27.7^{\circ} \mathrm{N}, 118^{\circ} \mathrm{E}\right)$, Wuyishan $\left(26.4^{\circ} \mathrm{N}\right.$, $\left.116.4^{\circ} \mathrm{E}\right)$. (2)

28. S. yao i Theodor, 1958 [1] \{1\}

[Theodor, O: 1958, 35-36, 50; Leng, YJ: Ann. Bull. Soc. Prasitol., Guangdong Province, 1985, 7:190-192]

Holotype \& Paratypes: NHML

Jiangxi: Jiujiang $\left(29.7^{\circ} \mathrm{N}, 115.9^{\circ} \mathrm{E}\right)$. (1)

29. S. zbengjiani Leng \& Yin, 1983 [14] \{4\}

[Leng, YJ \& Yin, ZC: Ann. Trop. Med. Parasitol., 1983, 77(4):426-428]

Holotype \& Paratypes: FMJNU \& NHML

Distribution: North, Maerkang (Barkam, $\left.31.9^{\circ} \mathrm{N}\right)$, Sichuan; East, Pengze $\left(116.5^{\circ} \mathrm{E}\right)$, Jiangxi; Southwest, Dali $\left(25.6^{\circ} \mathrm{N}\right.$, $100.1^{\circ} \mathrm{E}$ ), Yunnan covering 14 counties in 4 provinces. Hubei: Laifeng, Shennongjia, Wudangshan. (3)

Jiangxi: Jiujiang, Pengze. (2)

Sichuan: Lixian, Maerkang (Barkam), Maowen, Nanping, Wenchuan, Xiaojin. (6)

Yunnan: Dali, Huize, Yanjin. (3)

30. S. zhongi Wang \& Leng, 1991 [2] \{1\}

[Wang, HB \& Leng, YJ: Ann. Bull. Soc. Parasitol., Guangdong Province, 1991, 11(13):105-108]

Holotype \& Paratypes: FMJNU

Zhejiang: Songyang $\left(28.4^{\circ} \mathrm{N}, 119.4^{\circ} \mathrm{E}\right)$ and Zhoushan (Putuoshan, $\left.30^{\circ} \mathrm{N}, 122.4^{\circ} \mathrm{E}\right)$. (2) 


\section{g. Subgenus Parrotomyia Theodor, 1958}

[Theodor, O: 1958:33-42]

Five species of Parrotomyia have been found in China $S$. sumbarica distributes in North Xinjiang between 42.8 $44.4^{\circ} \mathrm{N}$ and $84.6-93.4^{\circ} \mathrm{E}$. S. barraudi. S. kwangsiensis, S. lud$n i c k i$ and $S$. yiniare members of Oriental Region, they are distributed in the south of Changiiang river. S. barraudi is the most common one, it covers 60 counties and cities of 16 provinces, autonomous regions and special zones between $21.4-33.1^{\circ} \mathrm{N}$ and $98.5-121.6^{\circ} \mathrm{E}$. And in the south it opens to Bangladesh, Burma, Cambodia, India, Indonesia, Laos, Malaysia, Thailand and Vietnam and in the east to Japan.

\section{S. barraudi Sinton, 1929 [60] \{17\}}

[Sinton, JA: Ind. J. Med. Res., 1929, 16(3):716-724; Raynal J \& Gaschen, H: Bull. Soc. Path. Exot., 1935, 28(2):113-118; Quate, LW: Pacific Insects, 1962, 4:251-267]

Chinese Specimen: FMJNU \& SIPD

Distribution: North, Xiangyang $\left(32^{\circ} \mathrm{N}\right)$, Hubei; East, Taidong $\left(121.1^{\circ} \mathrm{E}\right)$, Taiwan; South, Mengla $\left(21.4^{\circ} \mathrm{N}\right)$, Yunnan; West, Luxi $\left(98.5^{\circ} \mathrm{E}\right)$, Yunnan covering 60 counties and cities in 14 provinces, one autonomous region and two special zones. In the south it opens to Bangladesh, Burma, Cambodia, India, Indonesia, Laos, Malaysia, Thailand and Vietnam and east to Japan. Anhui: Boxian, Chuxian, Huangshan, Linquan, Shexian, Shitai, Taihe, Yuexi. (8)

Fujian: Chong'an. (1)

Guizhou: Congjiang. (1)

Guangdong: Zhanjiang. (1)

Guangxi: Guiping, Lingyun, Wuming, Wuzhou. (4)

Hainan: Baisha, Nada. (2)

Hong Kong. (1)

Hubei: Jingmen, Xiangyang, Yicheng. (3)

Hunan: Huayuan. (1)

Jiangsu: Nanjing. (1)

Jiangxi: Dayu, Jiujiang, Pengze. (3)

Macao. (1)

Shaanxi: county unknown.

Sichuan: Changning, Chongqing, Emei, Gaoxian, Gongxian, Guanxian, Hejiang, Jiang'an, Junlian, Leshan, Maowen, Nanchuan, Pengxian, Rongxian, Wenchuan, Wulong, Xiaojin, Xingwen, Yibin, Zigong. (20)

Taiwan: Hualian, Taibei, Taidong. (3)

Yunnan: Baoshan, Huize, Kunming, Luxi, Luxi, Mengla, Mengzi (zhicun), Yanjin. (8)

Zhejiang: Jiande, Zhoushan (Putuoshan). (2)

32. S. kwangsiensis Yao \& Wu, 1941 [6] \{3\}

[Yao, YT \& Wu, CC: Chn. med. J., 1941, 59:67-76; Chen, HT \& Hsu, PK et al.: Acta Ent. Sin., 1955, 5(3):295-306; Leng, YJ: Acta Entomol. Sin., 1964, 13(1):118-128]

Synonyms:

1. S. barraudi kwangsiensis Yao \& Wu, 1941

2. S. barraudi siulamensis Chen \& Hsu, 1955

Holotype \& Paratypes: ZUMS

Taxonomy: Here $S$. $b$. siulamensis is treated as a synomym of $S . b$. kwangsiensis and $S . b$. kwangsiensis is treated as a isolated species.

Distribution: North, Guangzhou $\left(23.1^{\circ} \mathrm{N}\right)$, Guangdong; East, Zhongshan $\left(113.3^{\circ} \mathrm{E}\right)$, Guangdong; South, Baisha $\left(19.2^{\circ} \mathrm{N}\right)$,
Hainan; West, Debao (106.6 ${ }^{\circ}$ ), Guangxi covering 6 counties of two provinces and one autonomous region in the southeastern corner of China.

Guangdong: Guangzhou, Zhongshan (Xiaolan, Siulam). (2) Guangxi: Debao, Nanning. (2)

Hainan: Baisha, Danxian. (2)

33. S. rudnicki Lewis, 1978 [2] \{1\}

[Lewis, DJ: Bull. Brit. Mus. (NH), Entom. Ser., 1978, 37(6):264265; He, MS \& Leng, YJ: Ann. Bull. Soc. Parasitol., Guangdong Province, 1991, 11(13):95-98]

Chiinese Specimen: FMJNU

Yunnan: Mengla $\left(21.4^{\circ} \mathrm{N}, 101.5^{\circ} \mathrm{E}\right)$ and Simao $\left(22.7^{\circ} \mathrm{N}\right.$ $\left.100.9^{\circ} \mathrm{E}\right)$. (2)

This fly is living in tropical rainforest and also found in Indonesia and Malaysia.

34. S. sumbarica Perfiliew, 1933 [4] \{1\}

[Perfiliew, PP: Zool. Anzeiger, 1933, 51(7/8):221-227; Guan, LR et al.: Endem. Dis. Bull., 1987, 2(1):36-43]

Chinese Specimen: SIPD

Distribution: Northwest, Usu $\left(44.4^{\circ} \mathrm{N}, 84.6^{\circ} \mathrm{E}\right)$; East, Qitai $\left(89.5^{\circ} \mathrm{E}\right)$; South, Turpan $\left(42.9^{\circ} \mathrm{N}\right)$; in the south of Jungger Basin. This fly is also found in Afhganistan, Iran, Iraq, Turkmenistan and Uzbekistan

Xinjiang: Anjihai, Qitai, Turpan, Usu. (4)

35. S. yini Leng \& Lin, 1991 [3] \{2\}

[Leng, YJ \& Lin, LS: Ann. Bull. Soc. Parasitol., Guangdong Province, 1991, 11(13):101-104]

Holotype \& Paratypes: FMJNU

Fujian: Chong'an $\left(27.7^{\circ} \mathrm{N}, 118^{\circ} \mathrm{E}\right)$ and Wuyishan $\left(26.4^{\circ} \mathrm{N}\right.$, $\left.116.4^{\circ} \mathrm{E}\right)$. (2)

Sichuan: Wulong $\left(29.3^{\circ} \mathrm{N}, 107.7^{\circ} \mathrm{E}\right)$. (1)

\section{h. Subgenus Sergentomyia s. str. França \& Parrot, 1920}

[Franca, C \& Parrot, L: Bull. Soc. Path. Exot., 1920, 13(8):695708]

Two species are reported, S. sinkiangensis and S. sintoni, from Xinjiang and the latter was found also in Afganistan, Egypt, iran, Iraq, Kuwait, Turkey, and Uzbekistan.

36. S. sinkiangensis Leng, Lane \& Lewis, 1987 [20] \{3\} [Leng, YJ, Lane, RP \& Lewis, DJ: Ann. Bull. Soc. Parasitol., Guangdong Province, 1987, 8(9):40-43]

Synonym: S. minutus sinkiangensis Ting \& Ho, 1962 [Ding, ST \& Ho, KT: Acta Entomol. Sin., 1962, 11(4):388-393] Lectotypes: FMJNU \& NHML

Taxonomy: S. sinkiangensis was wrongly treated and named as S. minutus sinkiangensis by Ting \& Ho in 1962. Dr. RP Lane pointed it out that if it were a subspecies it should be a member of Group antennatus of Abonnec (1972) instead of minutus. This fly was redescribed and renamed by Leng, Lane and Lewis (1987) according to the lectotypes. Distribution: A desert, semi-desert and grassland dweller. North, Karamay $\left(45.6^{\circ} \mathrm{N}\right)$, Xinjaing; East, Ejin Qi $\left(101^{\circ} \mathrm{E}\right)$, Inner Mongolia; South, Yecheng $\left(37.8^{\circ} \mathrm{N}\right)$, Xinjiang; West, Artux $\left(76.1^{\circ} \mathrm{E}\right)$, Xinjiang covering 20 counties along the north of Old Silk Road. 
Gansu: Dunhuang (might be other species awaiting for confirmation, Prof. He Xun CAO, 1989). (1)

Inner Mongolia: Ejin Qi. (1)

Xinjiang: Aksu, Artux, Anjihai, Bachu, Hami, Karamay, Kashi (Kaxgar), Keping, Kuqa, Shache, Shanshan, Shayar, Tarim, Toksun, Turpan, Usu, Wensu, Yecheng. (18)

S. sinkiangensis is considered a vector of lizard leishmaniasis in China according to experimental and natural infection and its close bionomic relationship with lizard. Natural infection with a rate of $15.4 \%$ has been estimated in Ejin Banner, Inner Mongolia (Guan 1991, 1994).

37. S. sintoni Pringle, 1953 [5] \{1\}

[Pringle, G: Bull. ent. Res., 1953, 43:707-734]

Synonym: S. aparklensis Perfiliew, 1933 [Perfiliew, PP: Zool. Anzeiger., 1933, 51(7/8):221-227; Jin, CF, Xiong, KH: Edem. Dis. Bull., 1987, 1(2):134-136]

Chinese Specimen: SIPD

Distribution: This fly living in desert, semi-desert and grassland of North Xinjiang around Jungger Basin. Northeast at Karamay $\left(45.6^{\circ} \mathrm{N}, 84.8^{\circ} \mathrm{E}\right)$; Southeast at Shanshan $\left(42.8^{\circ} \mathrm{N}\right.$, $\left.90.2^{\circ} \mathrm{E}\right)$.

Xinjiang: Jungger Basin (southwestern part), Karamay, Mosuowan, Shanshan, Turpan. (5)

\section{i. nicnic Group Theodor, 1948}

[Theodor, O: Bull. ent. Res., 1948, 9(1):102-103]

Two species are recorded in this group, which is distributed in South and Southwest China. S. campester is common in Hainan and $S$. bailyi in Sichuan. The north border of $S$. bailyi is at Guangyuan $\left(32.4^{\circ} \mathrm{N}, 105.8^{\circ} \mathrm{E}\right)$, Sichuan and that of $S$. campester is at Emei $\left(29.6^{\circ} \mathrm{N}, 103.4^{\circ} \mathrm{E}\right)$ while in the south both of them open to Cambodia, India, Laos, Pakistan, Thailand and Vietnam.

Taxonomy: After a comparative study in morphology and geographical distribution Leng (1980) considered bailyi and campester are two different species even Quate (1962) synonymized campester to bailyi.

38. S. bailyi Sinton, 1931 [15] \{4\}

[Sinton, JA: Ind.J. med. Res., 1931, 18(3):821-829; Leng, YJ: Acta Jinan Univ. (nat. Sci.), 1980, 2(2):23-30]

Chinese Specimen: FMJNU

Distribution: Northwest, Jinchuan $\left(31.4^{\circ} \mathrm{N}, 102^{\circ} \mathrm{E}\right)$, Sichuan; Southeast, Danxian $\left(19.5^{\circ} \mathrm{N}, 109.5^{\circ} \mathrm{E}\right)$, Hainan covering 15 counties and cities in 4 provinces of South and Southwest China.

Guangdong: Zhanjiang. (1)

Hainan: Danxian(Nanfeng), Nada. (2)

Sichuan: Gaoxian, Gongxian, Guangyuan, Jiang'an, Jinchuan, Junlian, Nanchuan, Rongxian, Yibin, Zigong. (10)

Yunnan: Longling, Mengla. (2)

39. S. campester (Sinton, 1931) Leng, 1980 [20] \{4\} [Sinton, JA 1931: see above; Raynal, J \& Gaschen, H: Bull. Soc. Path. Exot., 1934a, 27(6):564-569, 1934c, 27(9):858862; Leng, YJ: Acta Jinan Univ. Nat. Sci., 1980, 2(2):23-30]

Synonym: S. bailyi campester Sinton, 1931

Chinese Specimen: FMJNU
Distribution: North, Emei $\left(29.6^{\circ} \mathrm{N}\right)$, Sichuan; East, Wenchang $\left(110.7^{\circ} \mathrm{E}\right)$, Hainan; South, Yaxian $\left(18.2^{\circ} \mathrm{N}\right)$, Hainan; West, Shidian $\left(99.1^{\circ} \mathrm{E}\right)$, Yunnan covering 20 counties in 4 provinces. Guangdong: Zhanjiang. (1)

Hainan: Baisha, Baoting, Dongfang, Danxian, Haikou, Lingao, Lingmen, Lingshui, Nada, Qiongdong, Qionghai, Tunchang, Wanning, Wenchang, Yaxian. (15)

Sichuan: Emei, Zigong. (2)

Yunnan: Shidian, Simao. (2)

\section{j. Ungrouped}

Two morphologically strange Sergentomyia, S. fanglianensis Leng, 1964 from Hainan and $S$. yunnanensis He \& Leng from Yunnan are included here awaiting for further study to classify their taxa of ranks for subgenera.

40. S. fanglianensis Leng, 1964 [1] \{1\}

[Leng, YJ: Acta Entomol. Sin., 1964, 13(1):118-121]

Holotype \& Paratypes: FMJNU

Hainan; Baisha $\left(19.2^{\circ} \mathrm{N}, 109.4^{\circ} \mathrm{E}\right)$. (1)

41. S. yunnanensis He \& Leng, 1991 [1] \{1\}

[He, MS \& Leng, YJ: Ann. Bull. Soc. Parasitol., Guangdong Province, 1991, 11(13):95-98]

Holotype \& Paratypes: FMJNU

Yunnan: Yuanjiang $\left(23.5^{\circ} \mathrm{N}, 101.9^{\circ} \mathrm{E}\right)$. (1)

\section{k. Species needing further study}

42. S. pooi Yao \& Wu, 1941 [1] \{1\}

[Yao, YT \& Wu, CC: Chn Med.J., 1941, 59:67-76]

Holotype \& Paratypes: SIPD

Guangxi: Debao $\left(23.3^{\circ} \mathrm{N}, 106.6^{\circ} \mathrm{E}\right)$. (1)

No further confirmation of the presence of this species from China and other part of the world after more than 54 years.

43. S. suni Wu, 1954 [7] \{3\}

[Wu, CC: Acta Ent. Sin., 1954, 4(3):287-288; Hsiung, GH, Guan, LR \& Jin, CF: Acta Entomol. Sin., 1981, 24(4):430-431]

Holotype \& Paratypes: SIPD

Distribution: Northeast, Taiyuan $\left(37.8^{\circ} \mathrm{N}, 112.5^{\circ} \mathrm{E}\right)$, Shanxi; Southwest, Wenchuan $\left(31.4^{\circ} \mathrm{N} .103 .6^{\circ} \mathrm{E}\right)$.

Shaanxi: Xi'an, Yichuan. (2)

Shanxi: Jixian, Liulin, Taiyan. (3)

Sichuan: Nanping, Wenchuan (Weizhou). (2)

Taxonomy: The original paper only described one imconplete female fly from Xi'an, Shaaxi Province. Hsiung et al. (1981) reported five males and four females from a place (Weizhou) in Sichuan province far south from the original site with the pharynx similar to but the cibarial cavity different from the original description. No details from Shanxi's report except a name with distribution (Lu, 1981a).

44. S. turfanensis Hsiung, Guan \& Jin, 1981 [4] \{1\} [Hsiung, KH, Guan, LR \& Jin, CF: Acta Entomol. Sin., 1981, 24(4):432-433]

Holotype \& Paratypes: SIPD

Xinjiang: Bole, Shawan, Turpan, Urumqi. (4)

Taxonomy: The original description provided an insufficiently reliable and inadequate comparison for identifying a new species, but it may be a new record for China. 
Diagrammatic distribution of Phlebotomine sandflies in China
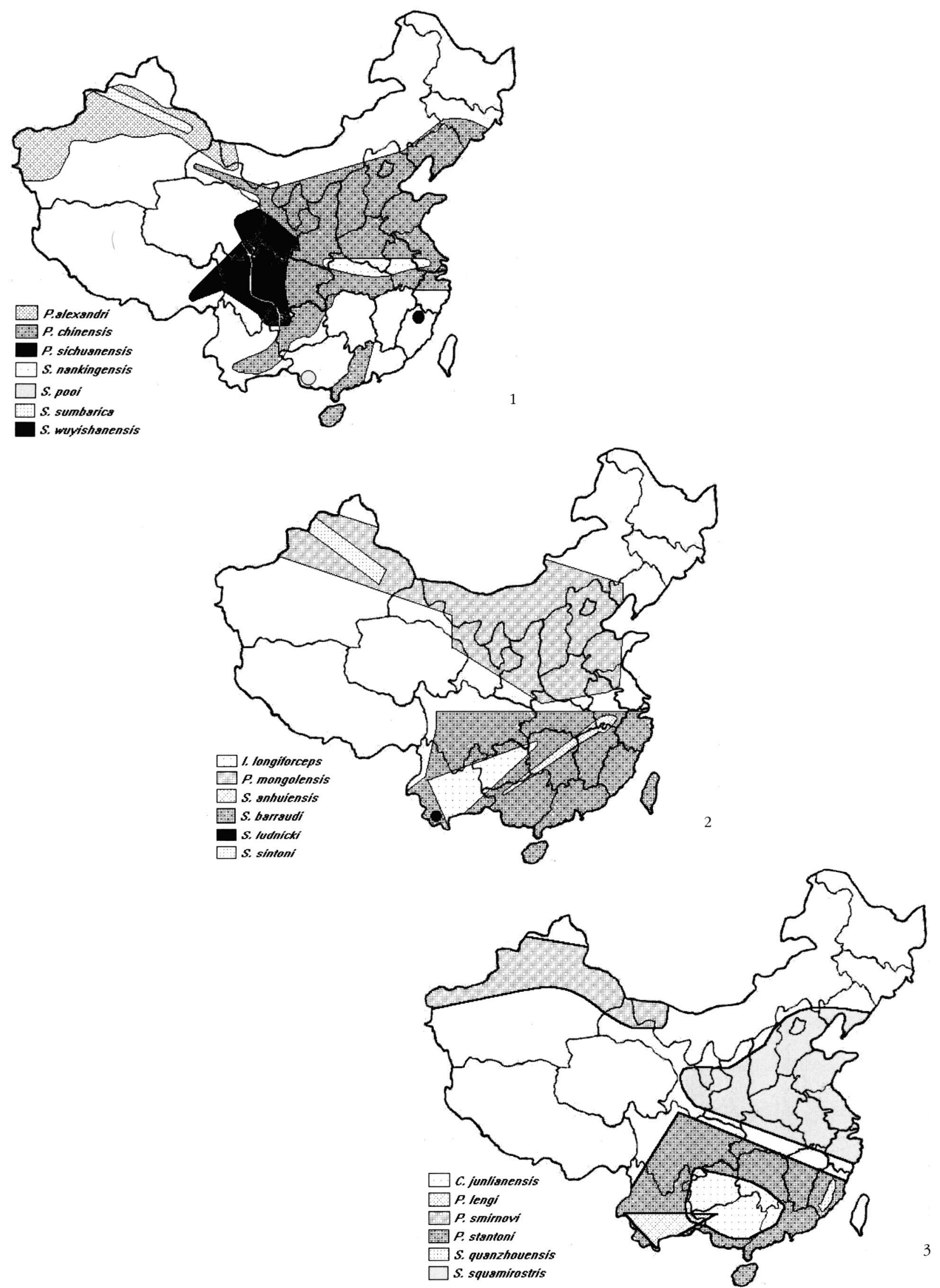


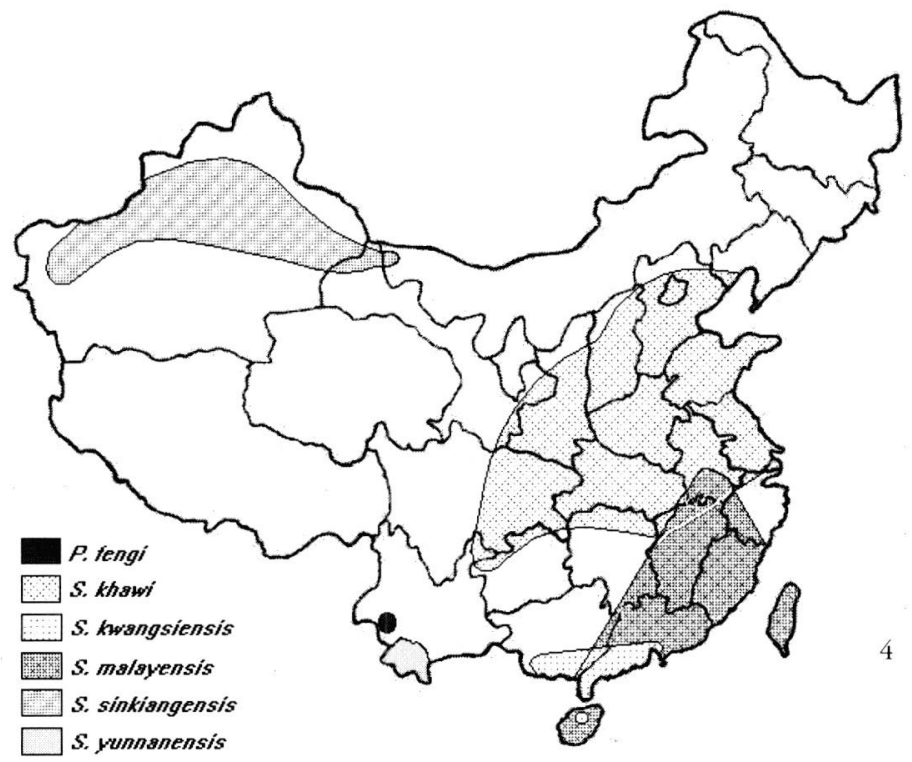

Diagrammatic distribution of Phlebotomine sandflies in China
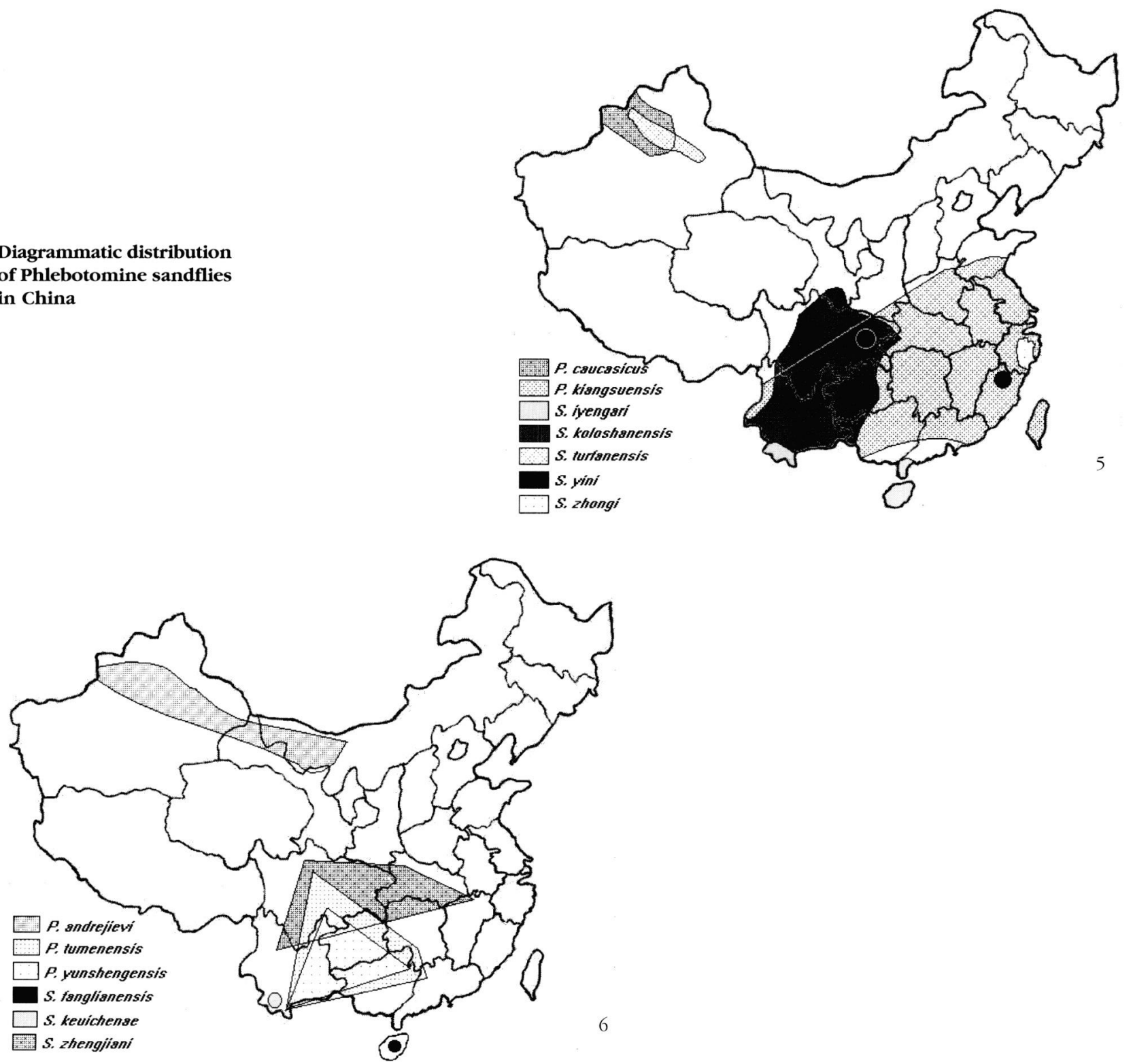


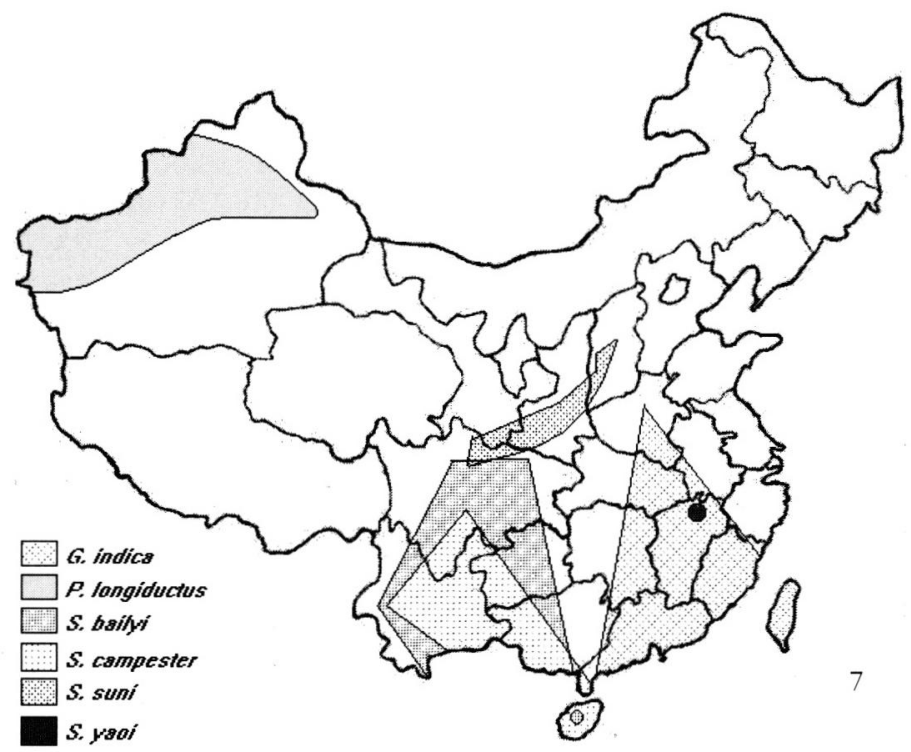

\section{F. The names}

\section{OF CHINESE PHLEBOTOMINES NOT INCLUDED}

\section{S. fukienensis Tang \& Tang, 1959}

[Tang, CC \& Tang, CT: Acta of Fukien Normal College, 1959, (1):161-176]

Fujian: Fuzhou.

Only each one of an incomplete male and a female were described without necessary characters for species identification but it is obviously a member of Sergentomyia.

\section{S. fupingensis Wu, 1954}

[Wu, CC: Acta Entomol. Sci., 1954, 4(3):288-290]

Shaanxi: Fuping.

It was only one incomplete female described belonging to subgenus Sergentomyia but no further evidence to comfirm the presence of such fly in China during the past 41 years.

3. S. kachekensis Yao \& Wu, 1938

[Yao YT \& Wu, CC: Trans. 10th Congr. FEATM, 1938a, 2:773-811]

Hainan: Qiongzhong.

Type specimen lost. According to the original data it was only one male described more or less like that of $S$. kwangsiensis. No further evidence for the presence of it during the past 57 years.

\section{ACKNOWLEDGEMENTS}

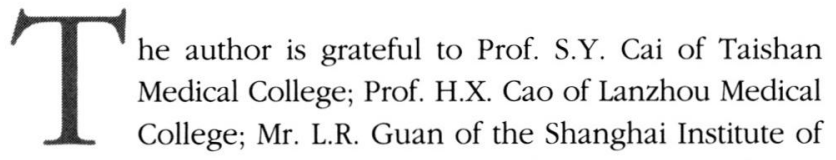

Parasitic Diseases, Chinese Academy of Preventive Medicine;
Dr. P.Z. Liu of Shaanxi Institute of Endemic Diseases; Prof. Y.L. Lu of Shanxi Medical College; Mr. D.X. Ma of the Institute of Military Medicine, Xinjiang Military Area, Urumqi; Ningxia Anti-epidemic Station, Yinchuan; Shandong Institute of Parasitic Disease, Jining; Prof. Y.X. Yu of the Military Academy of Medical Sciences, Beijing; Dr. G.X. Zhang, the Director of Henan Academy of Medical Sciences; Prof. M.R. Zhang of Xi'an Medical University and Mr. W.H. Zhou, Vice Chairman, Anhui Association for Livestock Husbandry and Veterinary Medicine; Who helped in providing references and comments.

\section{REFERENCES}

ABOnNenc E. Les phlébotomes de la région éthiopienne (Diptera, Psychodidae). Mémoires de l'Office de la Recherche Scientifique et Technique d'Outre-Mer, 1972, N. 55, Paris (in French).

ABONNEnC E. \& LEgER N. Sur une classification rationnelle des Diptères Phlebotomidae. Cabiers de la Recherche Scientifique et Technique d'Outre-Mer (Entomologie Medicale et Parasitologie), 1976, 14, 69-78 (in French).

Adler S. \& TheOdor O. Transmission of disease agents by phlebotomine sandflies. Annual Review of Entomology, 1957, 2, 203-226 (in English).

Alves-Pires C., Ramos H.C., Ribeiro H. \& Easton E.R. Occurence of Sergentomyia (Parrotomyia) barraudi (Sinton, 1929) in Macau Parasite, 1996, 3, 91-93 (in English)

ARTEMIEv M.M. Revision of phlebotomine sandflies subgenus Adlerius (Diptera, Phlebotominae, Phlebotomus). J. Zoology, 1980, 59 (8), 1177-1191 (in Russian). 
ArTemiev M.M. \& Neronov, V.M. Distribution and ecology of sandflies of the Old World (genus Phlebotomus). The USSR Committee for the UNESCO Programme on Man and the Biosphere (MAB), 1984, p. 28-31, 70-71, 103-105, 107108, Institute of Evolutionary Morphology and Animal Ecology, USSR Academy of Sciences, Moscow (in Russian).

BolT R.A. Sandflies (Pblebotomus) in China and their relation to disease. Chn. med.J., 1915, 29, 78-86 (in English).

CAO H.X. Leishmaniasis and phlebotomine sandfly survey in Gansu. Acta of Lanzhou Medical College, 1984, (3), 33-36 (in Chinese).

CAO H.X. Personal Communication, 1994 (in Chinese).

Cates M.D. \& Lien J.C. The Phlebotomus of Taiwan. J. Med. Entomol., 1978, 7(5), 529-543 (in English).

Chen H.T., Hsu P.K. et al. Phlebotomus from Kwangtung Province, with description of a new variety. Acta Entomol. Sin., 1955, 5 (3), 295-306 (in Chinese, Eng. abstr.).

Compilation of Kala-azar research and survey in Xinjiang Ughur Autonomous Region, in: Compilation of Hygiene and Anti-epidemic Materials. Edited by Xinjiang Station of Antiepidemics (in Chinese).

(1966) The roles of two main phlebotomine sandflies in transmitting Xinjiang Kala-azar. 6, 74-78.

(1966) The Breeding place of phlebotomine sandflies in Artux District. 6, 79-81.

(1974) The epidemicity of Kala-azar in 1973 in Meiyaogou District, Turpan. 10, 48-53.

(1980) Evaluation of long term effect for eradicating Kalaazar in Suntak District, Artux. 12, 48-52.

(1982) General prospect of Anti-Kala-azar in The Autonomous Region in 1980-1982. 16, 135-138.

(1982) A preliminary survey of the incidence of Kala-azar in North Xinjiang. 16, 139-143.

Cross J.H., Gunning J.J., Drutz D.J. \& Lien J.C. Introduced leishmaniasis on Taiwan. Southeast Asian J. Trop. Med. Pub. Hlth., 1985, 16 (3), 381-386 (in English).

Cross J.H., Gunning J.J., Drutz D.J. \& Lien J.C. Autochthonous cutaneous-subcutaneous leishmaniasis of Taiwan. Am. J. Trop Med. Hyg., 1995a, 3 (4), 254-256 (in English).

Ding S.D., CaI Y.L., Xu S., Feng L.X. \& Yuan Y.Z. The life history of Pblebotomus kiangsuensis Yao \& Wu, 1938 and Sergentomyia bailyi Sinton, 1931, and some ecological observations. Acta Nanjing Medical College, 1985, 5, 215217 (in Chinese).

Ding S.D. \& Ho K.T. Notes on the Chinese species of genus Phlebotomus. Part IX, Sandflies in Sinkiang Urghur Autonomous Region with description of Phlebotomus minutus var. sinkiangensis N. var., Acta Entomol. Sin., 1962, 11 (4), 388-392 (in Chinese, Eng. Abstr.).

DMH (Department of Military Health), (Epidemiology and Medical Animals of China). General Logistics Department, 1979, PLA, Beijing (in Chinese).

França C. \& PARrot L. Introduction à l'étude systématique de Diptères du genre Phlebotomus. Bull. Soc. Path. Exot., 1920, 13 (8), 695-708 (in French).

França C. \& Parrot L. Essai de classification des phlébotomes. Archs. Inst. Pasteur Afr. nord, 1921, 1, 279-294 (in French).
GE N.L. The geographical distribution and identification of phlebotomine sandflies in Anhui Province. Postgraduate J. Jinan Univ., 1988, 4 (2), 104-110 (in Chinese).

GE, N.L. \& LENG Y.J. A survey of the phlebotomine sandflies in Anhui Province with description of a new species - Sergentomyia (Neophlebotomus) anbuiensis sp. nov. (Diptera: Psychodidae). Contr. Blood-sucking dipt. Ins., 1990, 2, 110-116 (in Chinese, Eng, abstr.).

GUAN L.R., Jin C.F. \& XU Y.X. New record of Chinese Sandflies. Acta Entomotax. Sin., 1981, 3 (7), 28 (in Chinese).

GUAN L.R., XU Y.X. et al. Studies on Leishmania in big gerbils and lizards and its sandfly vectors in Ejin Banner, Inner Mongolia Autonomous Region. Acta med. Acad. Chn., 1982, 4 (5), 263-266 (in Chinese, Eng. abstr.).

GUAN L.R. et al. Observation on the bionomics of Phlebotomus alexandri in Turfan, Xinjiang. Endem. Dis. Bull., 1987, 2 (1), 35-43 (in Chinese, Eng. abstr.).

Guan L.R., XU Y.X. \& JiA J.X. Leishmaniasis in Karamay V. Observation on the Bionomics of Sandflies in Karamay, Xinjiang, China. Endem. Dis. Bull. 1991, 6 (2), 55-61 (in Chinese, Eng. abstr.).

GUAN L.R., XU Y.X. et al. Investigation on the sandfly fauna in Nei-Monggol (Inner Mongolia), China. J. prac. parast. Dis., 1993a, 1 (1), 34-35 (in Chinese).

Guan L.R., Xu Y.X., ZuO X.P., Zhang S. \& CaI J.J. Studies on the living environment of great gerbil and its natural infection of Leishmania and sandfly vectors in North Xinjiang, China. Endem. Dis. Bull, 1994, 9 (4), 7-10 (in Chinese. Eng. abstr.).

HE M.S. \& LENG Y.J. A study of phlebotomine sandflies (Diptera: Psychodidae) in Yunnan Province, China. II. Phlebotomine sandflies of southern Yunnan with description of Sergentomyia yunnanensis sp. n. and Sergentomyia rudnicki Lewis, 1978. Ann. Bull. Soc. Parasitol., Guangdong Province, 1991, 11 (13), 95-98 (in Chinese).

HE K.Z., WANG J. \& HuANG C.M. A compilation of reference material of Kala-azar survey and research in China from 1950 to 1959. Scientific-technical Publisher of Shanghai, 1959, 115 p. (in Chinese).

HenNig W. Insekenfossilien aus der unteren Kreide, IV. Psychodidae (Phlebotominae), mit einer kritischen Ubersicht uber das phylogenetische System der Familie und die bisher beschriebenen Fossilien (Diptera), Stuttgarter Beitrage zur Naturkunde aus dem Staatlichen Museum fur Nuturkunde in Stuttgart, 1972, 241, 1-69 (in German).

Ho K.T., TAN C.C., CHEN D.H. \& WU C.C. Notes on the Chinese species of the genus Pblebotomus. VIII. Sandflies in the vicinity of Nankiang with description of a new species Phlebotomus nankingensis. Acta Entom. Sin., 1954, 4, 427-432 (in Chinese, Eng. abstr.).

Ho KT, Wang J. \& HuAng C.M. A compilation of reference material on Kala-azar survey and research in China 19501959. Shanghai Publisher for Science and Technology, 1959, Shanghai (in Chinese).

Hsiong (Xiong) K.H., WANG J. \& GuAN (Kuan) L.R. Two species of sandflies of subgenus Paraphlebotomus found in Northwest China. Acta Entomol. Sin., 1964, 13 (1), 141144 (in Chinese). 
Hsiung (Xiong) K.H., Guan L.R. \& Jin C.F. New records of sandflies and description of a new species Sergentomyia turfanensis sp. nov. in Southwest China. Acta Entomol. Sin., 1981, 24 (4), 430-435 (in Chinese, Eng. abstr.).

Huo S.L. The species and distribution of phlebotomine sandflies in Inner Mongolia. Hyg. Antiepid. Inner Mongol., 1985, 1 (1), 38 (in Chinese).

JiANG X.R. \& ZHAO G. Phlebotomine survey in Liupanshan Mountains. Ningxia Correspondence of Medicine and Drug, 1981, 21, 68-69 (in Chinese).

Jin C.F., XIONG K.H. et al. First note on Sergentomyia aparklensis Perfeliew, 1933 in China. Endem. Dis. Bull., 1987, 1 (2), 134-136 (in Chinese).

Killick-Kendrick R. Phlebotomine vectors of the leishmaniases: a review. Medical and Veterinary Entomology, 1980, 4, 1-24 (in English).

LENG Y.J., Some new records of Phlebotomus from Hainan Island with description of a new species - Phlebotomus fanglianensis sp. nov. Acta Entomol. Sin., 1964, 13 (1), 118-128 (in Chinese, Eng. abstr.).

LENG Y.J. (Leng Y.C.), Restudy of the taxonomy of Sergentomyia iyengari and its subspecies. Acta Entomol. Sin., 1977, 20 (3), 331-336 (in Chinese, Eng. abstr.).

LENG Y.J. The geographical distribution and identification of phlebotomine sandflies (Diptera: Psychodidae) in Guangdong Province. Collected essays on parasitological research in Zhanjiang. Zhanjiang Medical College Press, 1978, 1 , 1-18 (in chinese).

LENG Y.J. The retrospect and prospect of phlebotomine study in Guangdong Province. Bulletin of First Symposium of the Zhanjiang Society of Parasitology, 1979, 1 (1), 1-24 (in Chinese).

LENG Y.J. On the taxonomy of Sergentomyia bailyi Sinton, 1931 (Psychodidae, Phlebotominae) and its subspecies. Acta Jinan Univ. (Nat. Sci.), 1980, 2 (2), 23-30 (in Chinese, Eng. abstr.).

LENG Y.J. A review of Kala-azar in China from 1949 to 1959. Trans. Roy. Soc. trop. Med. Hyg., 1982, 76, 531-537 (in English).

LENG Y.J. A taxonomic catalogue of phlebotomine sandflies (Diptera: Psychodidae) of Guangdong, Fujian, Jiangxi, Hunan, Guizhou and Sichuan Provinces. Ann. Bull. Soc. Parasitol., Guangdong Province, 1985, 7, 190-192 (in Chinese).

LENG Y.J. Genus Grassomyia Theodor, 1958 (Diptera: Psychodidae) and the confirmation of Grassomyia indica Theodor, 1931 in China. J. Sci. Med. Jinan Univ., 1987, 2, 25-29 (in Chinese, Eng. abstr.).

LENG Y.J. A preliminary survey of lime stone caves of Sichuan and Guizhou Provinces, Southwest China, and description of a primitive new genus Chinius. Annals Trop. Med. Parasitol., 1987, 81 (3), 311-317 (in English).

LENG Y.J. A review of Leishmaniasis Research in China from 1960 to 1986. Jpn. J. Parasitol., 1988, 37 (3), 119-132 (in English).

LENG Y.J. A review of phlebotomine sandflies and their transmission of leishmaniasis in China. Jpn. J. Sanit. Zool., $1988 a, 39$ (4), 323-337 (in English).
LENG Y.J. \& CHIN C.T. Distribution of sandflies (Diptera: Psychodidae) in Liaoning Province, A preliminary report. Kunchong Zhishi, 1957, 3 (4), 167-170 (in Chinese).

LENG Y.J. \& HE M.S. A study of phlebotomine sandflies (Diptera: Psychodidae) in Yunnan Province, China. V. Phlebotomus (Larroussius) fengi sp. nov. Ann. trop. Med. Parasitol., 1994, 88 (5), 531-537 (in English).

LENG Y.J. \& He M.S. A study of phlebotomine sandflies(Diptera: Psychodidae) in Yunnan Province IV. Sergentomyia (Neophlebotomus) kueichenae sp. nov. Entomologia Sinica, 1995, 2 (1), 13-17 (in English with Chinese abstract).

LeNG Y.J., LANE R.P. \& Lewis D.J. The identity of two phlebotomine sandflies from Xinjiang, China. Ann. Bull. Soc. Parasitol., Guangdong Province, 1987, 8 (9), 40-43 (in Chinese).

LENG Y.J. \& LewIS D.J. The subgenus Euphlebotomus (Diptera: Psychodidae) in China, with description of a new species, Pblebotomus yunshengensis. Ann. Trop Med. Parasitol., 1987, 81 (3), 305-309 (in English).

LENG Y.J., LI S.H. \& WANG Y.T. Preliminary report on the taxonomy and ecology of phlebotomine sandflies (Diptera: Psychodidae) in Liaoning Province. Shenyang med. J., 1958, 1 (1), 66-69 (in Chinese).

LENG Y.J. \& LiN L.S. On a new phlebotomine sandfly (Diptera: Psychodidae), Sergentomyia (Parrotomyia) yini sp. n. with additional description of Sergentomyia barraudi kwangsiensis Yao \& Wu, 1941. Ann. Bull. Soc. Parasitol., Guangdong Province, 1991, 11 (13), 101-104 (in Chinese).

LENG Y.J., LiU Y.Q. \& HuANG W.D. New records of sandflies from Zhanjiang of China. Acta Zootax. Sin., 1979, 4 (2), 189 (in Chinese).

LENG Y.J., WANG H.B. \& GE N.L. A survey of sandflies (Diptera: Psychodidae) in Hubei Province, China. Parassitologia, 1991, 33 (Suppl. 1), 377-379 (in English).

LENG Y.J. \& YIN Z.C. The taxonomy of phlebotomine sandflies (Diptera: Psychodidae) of Sichuan Province, China, with descriptions of two species, Pblebotomus (Adlerius) sichuanensis n. sp. and Sergentomyia (Neophlebotomus) zhengjiani n. sp. Ann. Trop. Med. Parasitol., 1983, 77 (4), 421-431 (in English).

LENG Y.J. \& Zhang L.M. Two new species of phlebotomine sandflies found in Fujian Province, China (Diptera: Psychodidae). Acta Zootax. Sin., 1987, 12 (2), 192-199 (in Chinese, Eng. abstr.).

LENG Y.J. \& ZHANG L.M. Zoogeographical distribution of phlebotomine sandflies in China (Diptera: Psychodidae). Contr. Blood-sucking dip. Ins., 1991, 3, 86-102 (in Chinese, Eng. abstr.).

LENG Y.J. \& ZHANG L.M. Phlebotomus (Adlerius) sichuanensis: A potential vector of visceral leishmaniasis in southwestern mountainous areas of China. Chn J. Parasitol., Taipei, Taiwan, 1992, 5, 73-80 (in English).

LENG Y.J. \& ZHANG L.M. Check list and geographical distribution of phlebotomine sandflies in China. Annal Trop. Med. Parasitol., 1993, 87 (1), 83-94 (in English).

LENG Y.J. \& ZHANG L.M. A study of phlebotomine sandflies (Diptera: Psychodidae) in Yunnan Province, III. Phlebo- 
tomus (Adlerius) fengi sp. nov. Annals Trop. Med. Parasitol., 1994, 88 (5), 523-530 (in English).

LENG Y.J. \& Zhang L.M. Phlebotomus sichuanensis Leng \& Yin, 1983 (Diptera: Psychodidae) of high mountainous area, southwestern China. Sichuan J. Zool., 1994a, 13 (1), 9-14 (in Chinese).

LENG Y.J., Zhang L.M. \& LIU K.N. First record of phlebotomine sandfly from Xizang (Tibet), China. Contr. Blood-sucking dip. Ins., 1990, 2, 117-118 (in Chinese, Eng. abstr.).

Leng Y.J., Zhang L.M. \& Zhang B.X. A study of phlebotomine sandflies (Diptera: Psychodidae) in Yunan Province, China. I. Phlebotomine sandflies of southeastern and western Yunnan. Parassitologia, 1991, 33 (Suppl. 1), 373-375 (in English).

LENG Y.J. \& ZHANG Z.K. The geographical distribution and bionomics of Phlebotomus in Liaoning Province. Acta Parasitol. Sin., 1964, 1 (2), 201-209 (in Chinese, Eng. abstr.).

Leng Y.J., Zhang Z.K. \& Ji Y.Q. Studies on phlebotomine sandflies in Liaoning Province, Part II. Investigation of sandfly control by chemical insecticides and Chinese medical herbs in laboratory and field. Kunchong Zhishi 1963, 7 (3), 127-129 (in Chinese).

LewIS D.J., The phlebotomine sandflies (Diptera: Psychodidae) of the Oriental Region. Bull. Brit. Mus. (NH), Ent. Ser., 1978, 37 (6), 217-343 (in English).

LEwIS D.J. A taxonomic review of the genus Pblebotomus (Diptera: Psychodidae). Bull. Brit. Mus. (NH), Ent. Ser., 1982, 45 (2), 121-209 (in English).

LEwIS D.J. Phlebotomine sandflies (Diptera: Psychodidae) from the Oriental Region. Systematic Entomology, 1987, 12, 163-180 (in English).

Lu Y.L. A preliminary survey on phlebotomine sandflies in western Shanxi. Acta Entomotax. Sin., 1981, 3 (3), 178 (in Chinese)

Lu Y.L. The first record of Sergentomyia suni in Shanxi, Acta of Shanxi Medical College, 1981a, (3), 21-22 (in Chinese).

Lu Y.L., Wu Y.X. \& Zhang J. Phlebotomine sandflies of 11 counties and cities in Shanxi. Acta of Shanxi Medical College, 1983, 1, 7-9 (in Chinese).

Lu Y.L. \& QIaO J.D. et al. Fauna of phlebotomine sandflies in representative counties and cities of Yanbei District, Shanxi. Acta of Shanxi Medical College, 1984, 1, 18-20 (in Chinese).

Lu Y.L. \& QiaO Z.D. Phlebotomine sandflies in Jiexiu, Yangquan and Yumeng. Acta of Shanxi Medical College, 1985, 4, 3-4 (in Chinese).

Lu Y.L. \& QIAO Z.D. Phlebotomine sandflies in 35 representative counties and cities, Shanxi Province. Internal material, printed by Shanxi Medical College and Shanxi Anti-epidemic Station, Taiyuan, 1985a, pp. 9 (in Chinese).

MA D.X. A study of phlebotomine sandflies - vector of leishmaniasis in Xianjiang. Institute of Military Medicine, Xinjiang Military District, 1990, 19 p. (in Chinese).

Ma K.X. et al. (Kala-azar in Gansu). Edited by Gansu Bureau of Health, Gansu Publisher of Science \& Technology, February, 1987, Lanzhou (in Chinese).
MARZINOvSKY E. Phlebotomus caucasicus sp. n. Meditsinskoe Obozerenie, Moskva, 1917, 87(13/16), 611-614 (in Russian).

NEw R.R.C. \& LENG Y.J. Characterization of subspecies of Leishmania in China by isoenzyme electrophoresis. An interim report on work carried out in Jinan University Medical School under the auspices of the exchange agreement between Jinan University and the Liverpool School of Tropical Medicine, 1985, p. 1-9 (in English).

Newstead R. Notes on Phlebotomus, with description of new species. Part II. Bull. Ent. Res., 1914, 5, 179-192 (in English).

Newstead R. On the genus Pblebotomus. Part III. Phlebotomus major var. chinensis. Bull ent. Res., 1916, 7 (2), 191-192 (in English).

Newstead R. On a new species of Pblebotomus from Japan. Ann. Trop. Med. Parasitol., 1923, 17 (4), 531-532 (in English).

Nitzulescu V. A propos de Pblebotomus chinensis. Ann. Parasitol. bum. comp., 1931, 9 (3), 261-265 (in French).

Nitzulescu V. Essai de classification des Phlébotomes. Ann. Parasitol. hum. comp., 1931a, 9 (3), 271-275 (in French).

PARRot L. Notes sur les phlébotomes II. Sur quelques phlébotomes de la Bokhara (URSS). Archs. Inst. Pasteur Alger., 1928, 6 (1), 26-34 (in French).

PATTON W.S. Blood-sucking arthropods of medical and veterinary importance in China. Chn. med.J., 1926, 40 (6), 543545 (in English).

Patton W.S. \& Hindle E. Reports from the Royal Society's Kala-azar Commission in China, No. 6. Notes on the species of sandflies, genus Phlebotomus of North China. Proc. of R. Soc., Ser. B, 1926, 100 (705), 405-412 (in English).

PATTON W.S. \& Hindle E. The Nothe Chinese species of the genus Phlebotomus, Diptera-Psychodidae. Proc. R. Soc., Ser., 1928, 102 (720), 533-551 (in English).

PERFILIEw P.P. Uber neue Steckmucken aus Mittelasien (Turkmenistan). Zool. Anzeiger, 1933, 51 (7/8), 221-227 (in German).

PERFILIEw P.P. Data on the sandfly fauna of the USSR II. Trudy Voenne-Meditsinskoe Akademii im. SM Kirova, 1941, 25, 272-284 (in Russian)

Perfiliew (Perfil'ev) P.P. Fauna of USSR, Diptera, Phlebotomidae (Sandflies). Israel Program for Scientific Translations. Jeresalem, 1968, 3 (2), 1-363 (in English).

Pringle G. The sandflies (Phlebotominae) of Iraq. Bull. Ent. Res., 1953, 43, 707-734 (in English).

Quate L.W. \& Fairchild G.B. Phlebotomus sandflies of Malaya and Borneo. Pacific Insects., 1961, 3 (2), 203-222 (in English)

Quate L.W. A review of the Indo-Chinese Phlebotominae (Diptera: Psychodidae). Pacific Insects, 1962, 4, 251-267 (in English)

Raynal J. Sur une nouvelle espèce de Phlébotome de la Chine du Nord : Phlebotomus khawi nov. sp. Ann. Parasitol. bum. comp., 1936, 16 (6), 529-540 (in French).

Raynal J. Contribution à l'étude des Phlébotomes de la Chine du Nord. Arch. Inst. Pasteur Indochine, 1937, 7 (25), 3799 (in French). 
Raynal J. \& Gaschen H. Sur les phlébotomes d'Indochine, I. Présence de Pblebotomus barraudi (female) au Tonkin, Bull. Soc. Path. Exot., 1934, 27 (6), 559-563 (in French).

Raynal J. \& Gaschen H., Sur les phlébotomes d'Indochine, II. Présence de Phlebotomuus bailyi var. campester (female) au Tonkin. Ibid., 1934a, 27 (6), 564-569 (in French).

Raynal J. \& Gaschen H. Sur les phlébotomes d'Indochine, III. Pblebotomus stantoni Newstead, 1914 au Tonkin. Sur la synonymie de Pblebotomus maynei (male) Sinton, 1930 et de Phlebotomus stantoni (male). Ibid. 1934b, 27 (7), 670679 (in French).

Raynal J. \& Gaschen H. Sur les phlébotomes d'Indochine, IV. Présence de Pblebotomus bailyi var. campester Sinton, 1931 en Annam et Description de Phlebotomus bailyi campester (male). Ibid., 1934c, 27 (9), 858-862 (in French).

Raynal J. \& Gaschen H. Sur les phlébotomes d'Indochine, V. Présence de Pblebotomus barraudi Sinton, 1929, dans le Haut-Bassin du Fleuve-Rouge et description de Phlebotomus barraudi (mâle). Ibid., 1935, 28 (2), 113-118 (in French).

RAYNAL J. \& GASChEN H. Sur les phlébotomes d'Indochine, VII. Présence de Phlebotomus iyengari Sinton, 1933, en Indochine-Nord et description des deux sexes. Ibid., 1935a, 28 (6), 507-517 (in French).

Raynal J. \& Gaschen H. Sur les phlébotomes d'Indochine, VIII. Phlebotomus hivernus n. sp. Ibid., 1935 b, 28 (6), 582592 (in French).

Rondani C. Sopra una specie di Insetto Diptero, Memoria prime per servire alla Ditterologia italica, Parma, 13, 1840.

RONDANI C. Species italicae generis Hebotomi Rondani ex insectis Dipteris: frangmentum septimum ad inerviendam Dipterologiam italicum. Ann. Soc. Entom. France, 2 (1), 263-267 (in Italian), see Lewis, 1978.

SAF'JANOVA V.M. Specificity of sandfly and leishmania relationships. Ministry of Public Health, Central Institute for Advanced Medical Studies. 1967, 44 p., Leningrad (in Russian).

Seccombe A.K. Ready P.D. \& Huddleston L.M. A cataloque of Old World phlebotomine sandflies (Diptera: Psychodidae, Phlebotominae). Occasional Papers on Systematic Entomology, 1993, No. 8, 1-57. Intercept, Nat. Hist. Mus., London (in English)

SERGIEV V.P. Epidemiology of leishmaniasis in the USSR. p. 197-212, in: Lumsden W.H.R. \& Evans D.A. Biology of the Kinetoplastida, 1979, 2. xii +738 p. London \& New York (in English).

SHAKIRZYANOVA M.S. The systematics of the sandflies of Kazahkstan. Trudy Instituta Zoologi Akademii Nauk Kazakhskoi SSR, 1953, 1, 102-107 (in Russian).

Shandong Institute for Kala-azar, Survey and research of phlebotomine sandflies (Diptera: Psychodidae) in Shandong. Compilation of Shandong Institute for Kala-azar. Tai'an, 1962 , p. $248-300$ (in Chinese).

ShaO Q.F. Wang Z.H., Hang S.L. \& Zhang P.J. Surveillance of Kala-azar after under controlled. Chn.J. Epidem., 1982, 3 (1), 35-37 (in Chinese).
Sinton J.A. The synonymy of the species of Phlebotomus. Ind. J. Med. Res., 1928, 16 (2), 297-324 (in English).

SINTON J.A. Notes on some Indian species of the genus Phlebotomus Part 24. Phlebotomus barraudi n. sp. Ind. J. Med. Res., 1929, 16 (3), 716-724 (in English).

SinTON J.A. Notes on some Indian species of the genus Phlebotomus Part 27. Phlebotomus bailyi n. sp. Ind. J. Med. Res., 1931, 18 (3), 821-829 (in English).

SinTON J.A. Notes on some Indian species of the genus Phlebotomus Part 34. Phlebotomus iyengari n. sp. Ind.J. Med. res., 1933, 21 (1), 221-224 (in English).

Song B.C. Epidemiological surveillance of Kala-azar in Chaoyang District, Liaoning. Chn.J. Epidem., 1981, 2 (3), 193-194 (in Chinese).

TANG C.C. \& MAA T. On a new species of Phlebotomus found in Fukien, China. Res. Bull. Fukien. Acad., 1945, 1, 241254 (in English).

TANG C.C. \& TANG C.T. Notes on a newly found sandflies from Fukien (Pblebotomus fukienensis sp. nov.). Acta of Fukien Normal College, 1959, 1, 161-176 (in Chinese, Eng. abstr.).

Theodor O. On African sandflies, Bull. Ent. Res., 1931, 22 (4), 469-478 (in English).

Theodor O. On sandflies from Ceylon, Siam, Malay. Ind. $J$. Med. Res., 1938, 26 (1), 261-269 (in English).

Theodor O. Classification of the Old World species of the Subfamily Phlebotominae (Diptera: Psychodidae). Bull. Ent. Res., 1948, 39 (1), 85-115 (in English).

Theodor O. Die Fliegen der Palearktischen Region - 9c. Psychodidae - Phlebotominae. E. Schweizerbart'sche Verlasbuchbandlung (Nagele u. Obermiller), Stuttgart, 1958, 1$55 \mathrm{p}$ (in German).

TIng S.T. \& Ho K.T. Notes on the Chinese species of genus Phlebotomus, IX. Sandflies in Sinkiang Urghur Autonomous Region, with description of Phlebotomus minutus var. sinkiangensis n. var. Acta Entomol. Sin., 1962, 11 (4), 388393 (in Chinese, Eng. abstr.).

Townsend B.C., Chainey J.E., Crosskey R.W., Pont A.C., Lane R.P., Boorman J.P.T. \& Crouch C.A. A catalogue of the types of bloodsucking flies. Occasional Papers on Systematic Entomology, 1990, No. 7, pp. 182-371. Nat. Hist. Mus., London (in English).

Tsu Y.C. Phlebotomus found in Shanghai. Acta Entomol. Sin., 1957, 7 (4), 496 (in Chinese).

Wang C.T. \& Chang Y.S. A new sandfly, Pblebotomus tumenensis sp. n. found in Szechuan Province, China. Acta Entomol. Sin., 1963, 12 (4), 511-515 (in Chinese, Eng. abstr.).

WANG C.T. \& JiAng X.R. Epidemiological analysis of Kala-azar in Ningxia Hui Autonomous Region from 1974 to 1980. Ningxia Correspondence of Medicine and Drug, 1982, 25, 32-36 (in Chinese).

WANG C.S., Ku Y.M. \& YuAN T.C. New records of sandflies in Kweichow Province with description of a new species Sergentomyia longiforceps sp. nov. Acta Entomol. Sin., 1974, 17 (3), 334-338 (in Chinese, Eng. abstr.). 
WANG H.B. \& LENG Y.J. A study of phlebotomine sandflies (Diptera: Psychodidae) in Zhejiang Province with description of a new species, Sergentomyia (Neophlebotomus) zhongi. Ann. Bull. Soc. Parasitol., Guangdong Province, 1991, 11 (13), 105-108 (in Chinese).

Wang J., Peng X.D., Guo Y.K. \& Yang G.Y. A preliminary survey of epidemicity of Kala-azar in Xinjiang Urghur Autonomous Region. J. Epidemiol., 1966, 4 (1), 30-32 (in Chinese).

WANG J., QU J.Q. \& GUAN L.R. A study on the Leishmania parasite of the big gerbil in Northwest China. Acta Parasitol. Sin., 1964, 1 (2), 105-117 (in Chinese, Eng. abstr.).

Wang C.T. \& Wu C.C. (Kala-azar), People's Hygienic Publisher, 1956, p. 433-581, Beijing (in Chinese)

WANG Z.J., WU Z.J. \& He K.Z. Advances in investigation and studies on Kala-azar in China since 1960. J. Parasitol. parasit. Dis., 1983, 1, 65-73 (in Chinese, Eng. abstr.).

Wu C.C., Notes on the Chinese species of genus Phlebotomus, Part VII. Two new species of sandflies Pblebotomus suni and Phlebotomus fupingensis from Shensi Province. Acta Entomol. Sin., 1954, 4 (3), 281-292 (in Chinese, Eng. abstr.)

Xiong G.H., Guang L.R. \& GuO Y.K. A study of the Kalaazar vectors in Xinjiang. Res. Contr. Epidem. Dis., 1974, 4, 327-334 (in Chinese).

Xiong G.H. \& Jin C.F. On the classification of subgenus Larroussius Nitzulescu, 1931 and Phlebotomus wui stat. nov. (Diptera: Psychodidae). Chn. J. Parasitol. parasit. Dis., 1987, 5 (1), 45-48 (in Chinese, Eng. abstr.).

Xiong G.H., Wang J., Hu Y.D. \& Liu P.Z. Studies on the Bionomics of Phlebotomus alexandri in Kansu Province. Acta Entomol. Sin., 1963, 12 (4), 458-462 (in Chinese, Eng. abstr.).

Xiong G.H., Hu Y.D., Yang G.Y. \& Huang G.M. Studies on gerbil leishmaniasis in Sinkiang; its sandfly vectors and relation to man. Acta Parasitol. Sin., 1964, 1, 130-136 (in Chinese, Eng. abstr.).

Xu J.B. Present situation of visceral leishmaniasis in China. Parasitology Today, 1989, 5 (7), 224-228 (in English).

Xu J.B., Blang S.L., Evans D.A. \& Peters W. The characterization by isoenzyme electrophoresis of Leishmania isolated in the People's Republic of China. Trans. Roy. Soc. Trop. Med. Hyg., 1984, 78, 689-693 (in English).

Xu Y.Q. Phlebotomus found in Shanghai. Acta Entomol. Sin., 1957, 7 (4), 496 (in Chinese).

Xu Y.X., Guan L.R. et al. Leismaniasis in Kramay. I. Two cases of cutaneous leishmaniasis in Karamay, Xinjiang, China. Endem. Dis. Bull., 1989, 4 (2), 70-72 (in Chinese, Eng. abstr.).

YAN Q.Y. 1987 report on the surveillance of sandflies in Henan Province. Chn J. parasit. Dis. prev therap., 1988, 1 (1), 20 (in Chinese).

YAN Q.Y. 1983-1988 report on the surveillance of Kala-azar in Henan Province. Endem. Dis. Bull., 1989, 4 (3), 70-71 (in Chinese, Eng. abstr.).

YAN Q.Y. et al. 1991-1992 report on the surveillance of Kalaazar in Henan Province. Henan J. prev. Med., 1993, 4 (4), 234 (in Chinese).
YANG F.H. Uber die Verbreitung der Phlebotomen in NordChina und eine neue art des Phlebotomus mit Seiner aetiologischen Bedeutung fur die Papatacierkrankung in Peiping, 1926, IXth Medical Kongress (in German).

YANG F.H. Zur Kenntnis der Phlebotomen-Arten in China und zur Aetiologie des Phlebotomenfiebers mit einen Anhang uber die Verbreitung des Insekts in China. Transactions IXth Congress FEATM, Nanking, 1934, 1, 495-502 (in German).

YANG K.Y. \& XiONG G.H. A new subspecies of sandfly Phlebotomus major wui subsp. nov. from Sinkiang, China. Acta Parasitol. Sin., 1965, 2(4), 412-415 (in Chinese, Eng. abstr.).

YAo Y.T. \& WU C.C. Notes on a species of Phlebotomus newly found in Tsingkiangpu, North Kiangsu, China. Chn. med. J., 1938, (Suppl. 2), 527-537 (in English).

YAO Y.T. \& WU C.C. Notes on the Chinese species of genus Phlebotomus, II. Sandflies of Hainan Island. Trans. 10th Congr. FEATM, 1938a, 2, 773-811 (in English).

YAO Y.T. \& WU C.C. Notes on the Chinese species of genus Phlebotomus, III. Sandflies in Nanning and Tienpo, Kwangsi. Chn. med.J., 1941, 59, 67-76 (in English).

YAO Y.T. \& WU C.C. Notes on the Chinese species of genus Phlebotomus, IV. Diagnostic table for the Chinese species of sandflies with some remarks on their geographical distribution. Chn. med.J., 1941a, 60, 73-78 (in English).

YAO Y.T. \& WU C.C. Notes on the Chinese species of genus Phlebotomus - V. Some additional records of Pblebotomus from Yunnan Province, South China. Chn. med.J., $1941 b, 60,79-80$ (in English).

YAO Y.T. \& Wu C.C. The finding of Phlebotomus chinensis Newstead from Yunnan and its bearing on the transmission of Kala-azar in South China, with remarks on the success in infecting $P$. chinensis found in Tsingjiiangpu. Chn. med.J., 1941c, 60, 232-248 (in English).

YAO Y.T. \& WU C.C. Notes on the Chinese species of genus Phlebotomus, VI. Sandflies in Chunking, Szechuan, with description of a new species, Phlebotomus koloshanensis. J. Parasitol., 1946, 32, 87-90 (in English).

YIN Z.C. \& LENG Y.J. et al. The study of a new vector for visceral leishmaniasis, Phlebotomus sichuanensis Leng \& Yin, 1983. Scientific Report from Sichuan Institute of Parasitic Diseases, 1985, p 1-5, Chengdu (in Chinese).

YU K.W. \& CHOw M.P. et al. Imported Kala-azar: A case report. Chn. Med. J. (Taipei), 1992, 50 (5), 411-414 (in English).

Zhang L.M., HE M.S. \& WARD R.D. A study of phlebotomine sandflies (Diptera: Psychodidae) in Yunnan Province, V. Phlebotomus (Larroussius) lengi sp. nov. Annals Trop. Med. Parasitol., 1994, 88 (5), 531-537 (in English).

ZHANG L.M. \& LENG Y.J. A preliminary isoenzyme study on five species of phlebotomine sandflies in China. Parassitologia, 1991, 33, (Suppl. 1), 541-550 (in English).

ZHang Z.K. Sandflies in Liaoning Province. Trans, Liaoning zool. Soc., 1983, 4 (2), 41-43 (in Chinese, Eng. abstr.)

Zhong H.L. (Chung Huei-lan), Xu Z.B., CaO W.J. \& He L.Y. New types of Lymph gland leishmaniasis in China. Chn. med. J., 1982, 95 (4), 303-306 (in English). 